\title{
Determination of the Dissolution Slowness Surface by Study of Etched Shapes: II. Comparison of 2D Experimental and Theoretical Etching Shapes
}

\author{
T. Leblois $\left(^{*}\right)$, C.R. Tellier and T. Messaoudi \\ Laboratoıre de Chronométrıe, Électronique et Piézoélectrıcıté, ENSMM, \\ 26 chemin de l'Épitaphe, 25030 Besançon, France
}

(Recerved 1 July 1996, accepted 9 December 1996)

\begin{abstract}
PACS.81 10 A] - Theory and models of crystal growth, physics of crystal growth, crystal morphology and orientation

PACS.81.65 Cf - Surface cleaning, etching, patterning

PACS.82 20 Wt - Computational modeling; simulation
\end{abstract}

\begin{abstract}
The anisotropic etching behavior of quartz crystal in concentrated ammonium bifluoride solution is studied and analyzed in the framework of a tensorial model. This model allows to simulate bi- or three-dimensional etching shapes from the equation for the representative surface of the dissolution slowness. In this paper, we present experimental results such as surface profile and initially circular cross-sectional profiles of differently singly- or doubly-rotated cuts The polar diagrams of the dissolution slowness vector in several planes are deduced from experimental data The comparison between predicted surface and cross-sectional profiles and experimental results is detailed and shows a good agreement In particular, several examples give evidence that the final etched shapes are correlated to the extrema of the dissolution slowness. However, in several cases, experimental shapes cannot be simply correlated to the presence of extrema. Simulation gives effectively evidence for an important role played by more progressive changes in the curvature of the slowness surface. Consequently, analysis of data merits to be treated carefully
\end{abstract}

Résumé. - Nous nous proposons d'étudier et d'analyser à l'arde du modèle tensoriel de la dissolution l'attaque chimique anisotrope du cristal de quartz dans une solution concentrée de bifluorure d'ammonium. Ce modèle permet de simuler des formes usinées à deux ou trois dımensions à partır de l'équation de la surface représentatıve de la lenteur de dissolution du cristal de quartz. Dans cet article, nous présentons des résultats expérımentaux concernant des profils de surface et des sectıons initıalement cylındrıques de coupes à simple et double rotation Les diagrammes polaires du vecteur lenteur de dissolution dans différents plans sont déduits de données expérimentales. La comparaison entre les profils de surface et de section théorıques et les résultats expérımentaux est détallée et montre un bon accord. En partıculıer plusieurs exemples montrent que la forme finale est corrélée à la présence d'extrema de la lenteur de dissolution. Cependant, la corrélation entre résultats expérimentaux et théorıques n'est pas toujours sımple et mérıte une analyse soıgnée Pour conclure, le modèle 3D est appliqué pour prévoir la forme usinée d'un trou initialement circulaure dans une coupe tournée autour de l'axe $Y$ Le résultat théorıque est comparé avec la forme usinée expérimentale et montre un parfait accord.

(*) Author for correspondence (e-mall· Therese.Leblois@ens2m fr) 


\section{Introduction}

Chemical etching of quartz crystal has been carried out for many decades. Major works were devoted to the study of the crystal symmetry, of the ability to produce polished or preferentially etched surfaces [1-12]. Some people used chemical etching to study dislocations in natural and synthetic quartz $[13,14]$. Nowadays, more and more people are interested in the technique called micromachining. Initially, these techniques were developed for the microelectronic industry, especially on silicon [15-17]. But, in fact, micromachining of mechanical devices, which constitute the sensing element of sensors can be applied to other crystalline materials such as quartz [18-20].

We know that performances of sensors or resonators are greatly dependent on the geometry of the mechanical devices, specifically on the topology of the etched surfaces, on the lateral and corner undercutting [21-24]. The dependence on the geometry is of prime importance if one wants to miniaturize mechanical devices. So, the design of micromechanical devices with good metrological characteristics needs a theoretical prediction of their etched shapes. It is fundamental to have a simulation of the etched shapes for mechanical devices etched on several differently oriented cuts because some non conventional orientations of sensing elements may have very interesting properties such as large sensitivity or temperature compensation leading to new sensors applications.

During the last few years, the simulation of etched shapes has been based on the pioneering kinematic model given by Frank $[25,26]$ and later developed by Tellier et al. With the Frank's model, we can also construct geometrically the shapes of $2 \mathrm{D}$ devices obtained after an anisotropic etching under a mask $[27,28]$. Tellier et al. have recently proposed a numerical simulation of the shape of $2 \mathrm{D}$ and $3 \mathrm{D}$ etched micromechanical devices. This simulation is based on a tensorial model of the anisotropic etching [29-31], and starts with an analytical expression of the dissolution slowness $L(\varphi, \theta)$ in terms of the orientation $(\varphi, \theta)$ of surface elements. The representative surface of the dissolution slowness is generally determined from experımental data [32-34] related to $2 \mathrm{D}$ shapes The determination procedure remains rather difficult so that specific tests $[33,34]$ must be undertaken to verify the adequation of the proposed slowness surface.

This paper will be divided into four parts.

- In Section 2, we give the basis of the tensorial model for the anisotropic dissolution and explain the procedure to determine the dissolution constants which appear in the equation of the dissolution slowness

- In Section 3, we present experimental details and give experimental results about changes in surface texture of differently oriented cuts induced by prolonged etchings.

- In Section 4, we compare experimental and theoretical data in order to discuss the adequation of theoretical shapes derıved from simulation.

- In Section 5, we report some experiments related to mesa or membranes micromachined on two different cuts of quartz. We compare these results with those obtained by the 3D graphical simulation of etched shapes.

\section{Basis of the Theoretical Model}

This model [29-31] constitutes an extension of the kinematic model of dissolution proposed by Frank. As compared to previous works in which an approximate limited etching shape can be constructed geometrically $[27,28,35,36]$, this work presents the advantage to derive 

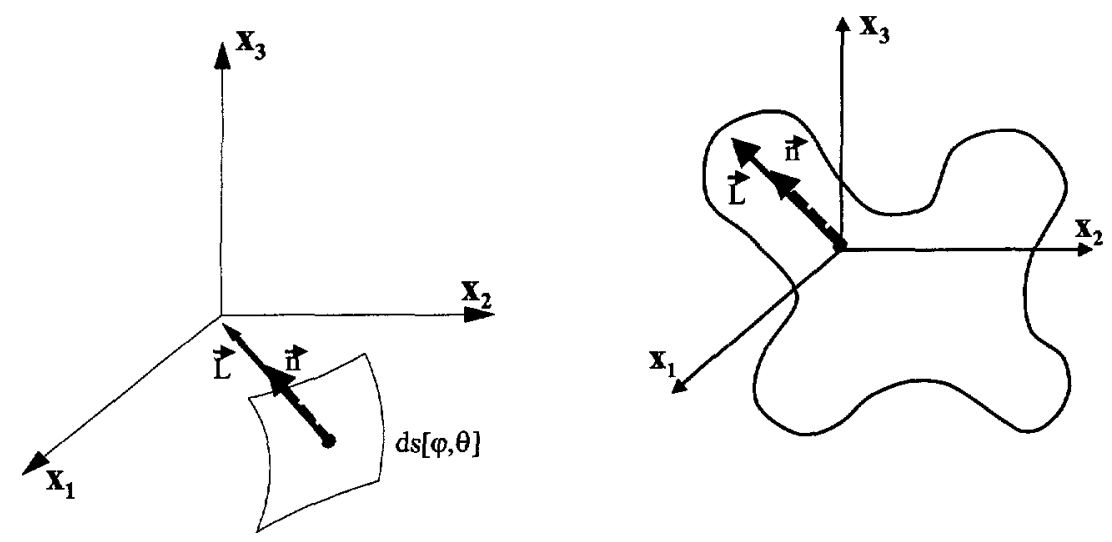

Fig 1. - Three-dimensional representation of the dissolution slowness surface.

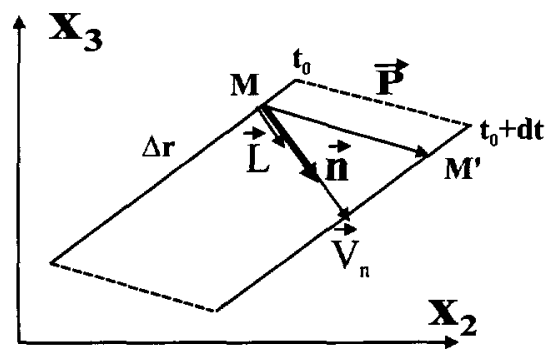

Fig 2. - Definition of the propagation vector $\mathbf{P}$

numerically 2D and 3D shapes. The surface of a crystal can be decomposed into successive planar facets corresponding to crystallographic planes. Tellier [31,34] has defined a vector called the dissolution slowness vector $\mathbf{L}$. This vector is associated to each surface element; its magnitude $L(\varphi, \theta)$ is the reciprocal of the dissolution rate and its direction is that of the inward normal unit vector $\mathbf{n}$ to the surface element. When the orientation of the element varies, the extremity of the vector $\mathbf{L}$ generates the dissolution slowness surface (Fig. 1). As the dissolution process only depends on the orientation, the trajectory of the surface elements given by $(\varphi, \theta)$ follows a straight line and can be described by a propagation vector $\mathbf{P}$ (Fig. 2). The components of this vector may be expressed in terms of the dissolution slowness vector. In addition, several works [31,37] give evidence that the propagation vector $\mathbf{P}$ lies perpendicular to the plane tangent to the dissolution surface at the point of corresponding orientation. Using this property with the dissolution slowness surface, we can construct numerically the etching shapes. Hence, we can generate more precisely the shape of samples as soon as the equation of dissolution slowness is known. The representative equation of the slowness surface can be expressed in terms of a polynomial relation involving the three components $\left(n_{1}, n_{2}, n_{3}\right)$ of the inward normal unit of $\mathbf{n}[29,31]$

$$
L(\varphi, \theta)=D_{0}+D_{\imath} n_{\imath}+D_{\imath \jmath} n_{\imath} n_{\jmath}+\ldots+D_{\imath \jmath k l} n_{\imath} n_{\jmath} n_{k} n_{l}+\ldots
$$

where $D_{0} . D_{\imath \jmath k l}$ are components of the dissolution tensors. 


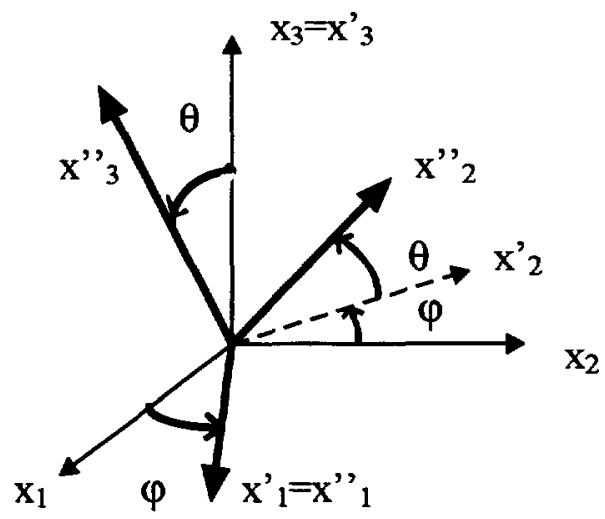

Fig 3. - Definition of the angles $\varphi_{0}$ and $\theta_{0}$.

The number of the dissolution constants is reduced according to the symmetry of the crystal $[30,33]$. We can also work with doubly rotated surface elements whose orientations are defined by two angles of cuts $(\varphi, \theta)$ according to the conventions specified in the IEEE standards on piezoelectricity (Fig. 3) [38]. So, expressing $\mathbf{L}$ in terms of the orientation angles $\varphi$ and $\theta$, we have for the crystal class 32 .

$$
L(\varphi, \theta)=S_{1}+S_{2}+S_{3}+S_{4}
$$

with

$$
\begin{aligned}
S_{1} & =\sum_{\jmath=0} A_{\jmath}(\cos \theta)^{2 \jmath} \\
S_{2} & =\sum_{l=0} \sum_{k=1} B_{k}(\cos \theta)^{2 k+1}(\sin 3 \varphi)^{3 l} \\
S_{3} & =\sum_{m=0} \sum_{\imath=0} C_{\imath}(\cos \theta)^{2 l+1} \sin \theta(\cos 3 \varphi)^{3 m} \\
S_{4} & =\sum_{p=3} D_{p} \sin \theta(\cos \theta)^{2 p} \cos 3 \varphi \sin 3 \varphi .
\end{aligned}
$$

$l$ and $m$ equal zero for $N_{\max }<9$ and appear for $N_{\max } \geq 3^{l+1}$ and $N_{\max }<3^{m+1}$ where $N_{\max }$ is the maximum rank of the tensors. $A_{\jmath}, B_{k}, C_{i}$ and $D_{p}$ are expressed in terms of independent dissolution constants $D_{0} \ldots D_{\imath \jmath k l}$. We observe that $S_{1}$ and $S_{3}$ include tensors of even rank and $S_{2}, S_{4}$ are expressed with terms of odd ranks. The major problem remains the experimental determination of the dissolution constants. At this point, the question we ask is: what is the maximum rank $N_{\max }$ to have to use to obtain a good representation of the dissolution slowness? The response is not simple In fact, it depends on the complexity of the observed etching shapes, which is really dependent on the magnitude, on the number and on the sharpness of the dissolution slowness [33]. But clearly, for quartz we have to retain at least two tensors of even and of odd ranks respectively.

For quartz and $\mathrm{NH}_{4} \mathrm{~F} \mathrm{HF}$ etchant, we use essentially dissolution constants related to tensors whose rank varies from 11 to 13 , a lot of tensors of smaller rank are supposed to be equal to zero. It is clear that in order to have a good representation of the dissolution slowness 
with tensors of high rank, we have to analyze carefully a lot of experimental results, related to several kinds of $2 \mathrm{D}$ etching shapes [33].

\section{Experimental Results}

3.1. Experimental Process. - Differently oriented wafers were cut in a quartz blank. The angles of cut $\left(\varphi_{0}, \theta_{0}\right)$ are determined by a double X-ray goniometer which gives an accuracy of $30^{\prime}$. Initially, surfaces and contours of circular plates were lapped with abrasive with decreasing grain diameters and finally optically polished. All etchings of quartz plates were made in a concentrated ammonium bifluoride solution $\left(\mathrm{NH}_{4} \mathrm{~F} \mathrm{HF}\right)$. The temperature of the etchant is controlled with an accuracy of $\pm 0.5 \mathrm{~K}$. After successive isothermal etchings, $2 \mathrm{D}$ etching shapes of the wafer are controlled by different means:

1. The etched surface texture of quartz samples is viewed by Scanning Electron Microscopy (S E.M). In addition, the surface profiles and textures are characterized using an Atomic Force Microscope (A.F.M.) with a maximum scanning size of $125 \times 125 \mu \mathrm{m}^{2}$. The tip of the cantilever is very small (about $0.2 \mu \mathrm{m}$ ) which is a real advantage compared with the mechanical surface profilometer where the diamond tip which has a finite diameter size close to $2 \mu \mathrm{m}$ induces a mechanical filtering for dissolution figures of small size.

2. We follow changes in the cross-sectional shape of initially cylindrical crystals with orientations $\left(\varphi_{0}, \theta_{0}\right)$ using a Talyrond analyzer which gives the out-of-roundness profiles of etched sections with respect to a last square circle.

We also present experimental micromachined holes. They are obtained by a conventional photolithographic process. Chemically inert masks are composed of chromium-gold evaporated films. After deposition, the masked samples endure a thermal treatment which induces a progressive restructuration of $\mathrm{Cr}$-Au film and a continuous decreasing of in-plane stresses. We then use conventional photolithographic process [39] to protect only some specific regions of the wafer. We start with initially circular masks of chromium and gold on the quartz surface in order to etch mesa or membrane structures. The samples are placed into a concentrated $\mathrm{NH}_{4} \mathrm{~F} \mathrm{HF}$ bath during several hours. In the final stage, the modification of initial circular contour shapes and development of convex or concave undercuttıngs are analyzed using a Scanning Electron Microscope.

3.2. The Orientation Dependence of the Surface Topography. - Figures 4 and 5 illustrate the evolution of the surface texture with the etching time for some singly and doubly-rotated quartz plates. Firstly, these figures give evidence that the geometrical features of etched surfaces are primarily governed by the orientation of cuts in accord with previous experimental works on singly-rotated quartz plates $[7,11,40]$. In particular, for doubly-rotated cut $Y+45\left(\theta_{0}=45^{\circ}, \varphi_{0}=90^{\circ}\right)$, etched surface texture for the two faces are strongly different. One face presents convex surfaces, the other is constituted by plane facets of various slopes (Fig. 5). The changes in the surface texture of the AT-16 $\left(\varphi_{0}=0, \theta_{0}=16^{\circ}\right)$ and BT-14 $\left(\varphi_{0}=0\right.$, $\theta_{0}=-14^{\circ}$ ) plates are investigated over the temperature range $318 \mathrm{~K}-360 \mathrm{~K}$ during the same period of time. The two cuts reveal different final geometrical textures. In the first stages of etching, the S.E.M. images show the influence of the inttial lapping process which creates a disturbed surface layer which in general $[41,42]$ dissolves more rapidly than the perfect planar crystallographic plane. We observe by S.E.M. that the AT-16 cut presents somewhat concave pits oriented in the $Z^{\prime}$ and $X^{\prime}$-directions. Concerning the BT-14 cut, we observe elongated dissolution figures aligned along the $Z^{\prime}$-direction. As noticed above the etched textures do not vary with the different temperatures, they are characteristic of the cut. 


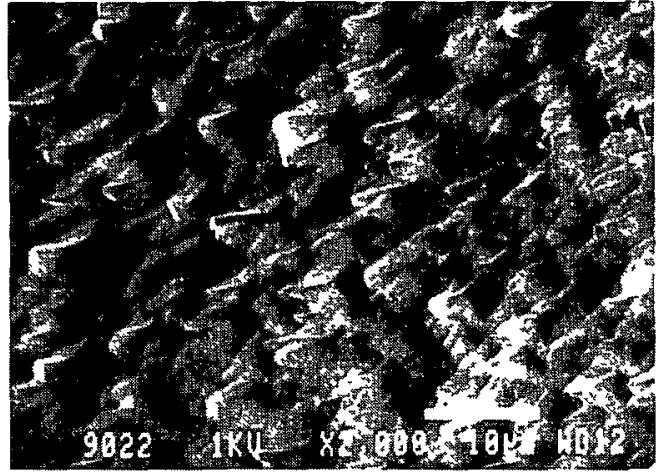

1)

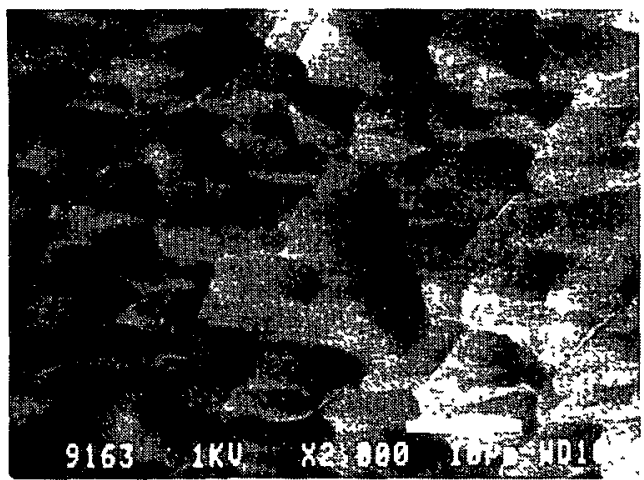

2)

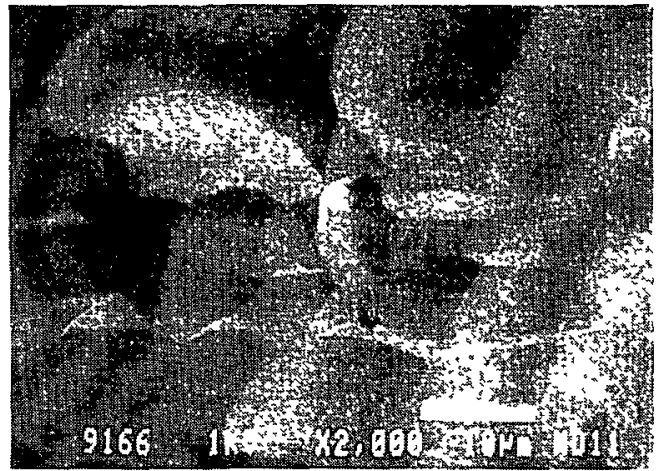

3)

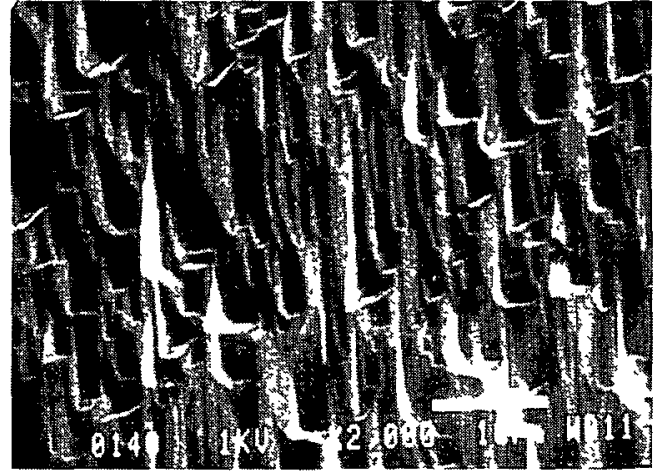

4)

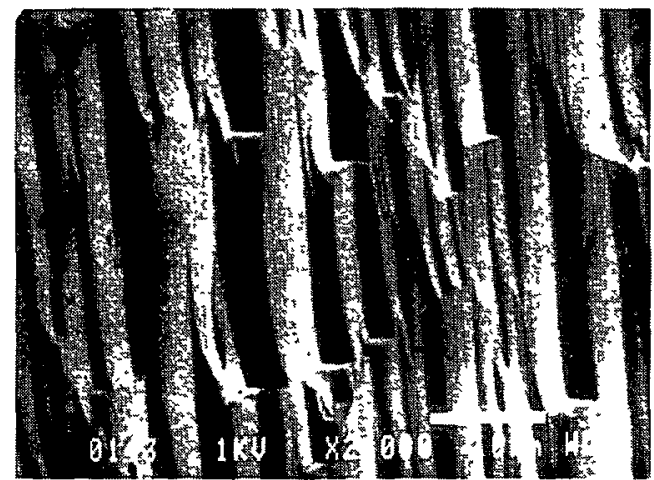

5)

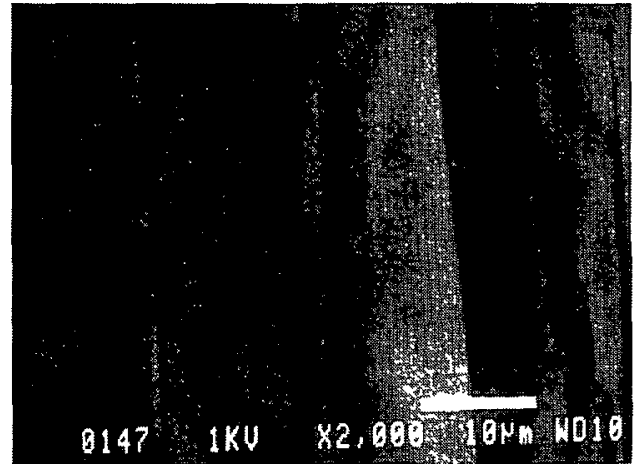

6)

Fig. 4 - Surface texture of AT and BT cuts 1.2 3: AT-16 cut after etching at 318,338 and $348 \mathrm{~K}$ during the same period 456 : BT-14 cut after etching at 318, 338 and $348 \mathrm{~K}$ during the same period.

These few examples confirm that the surface topography produced by chemical etching in concentrated $\mathrm{NH}_{4} \mathrm{~F} \mathrm{HF}$ is strongly connected to the orientation of the crystal plane, so that the tensorial model of anisotropic dissolution applies and we can undertake comparison between theoretical and experımental shapes. 


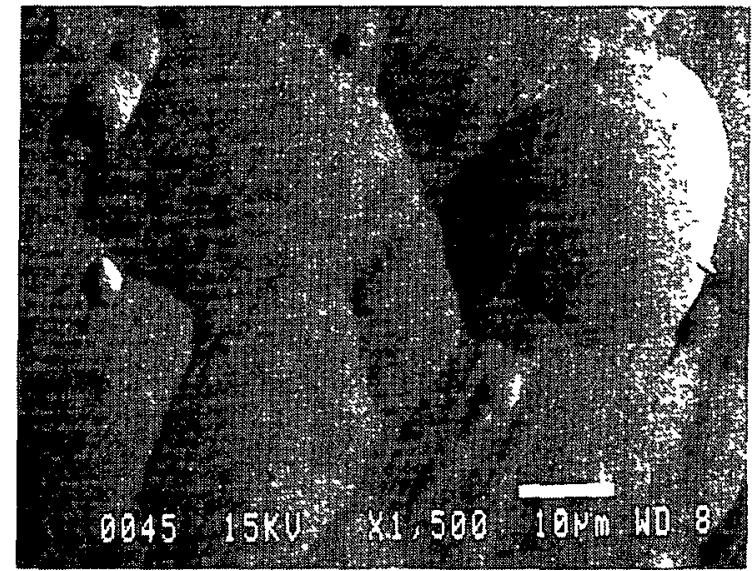

a)

b)

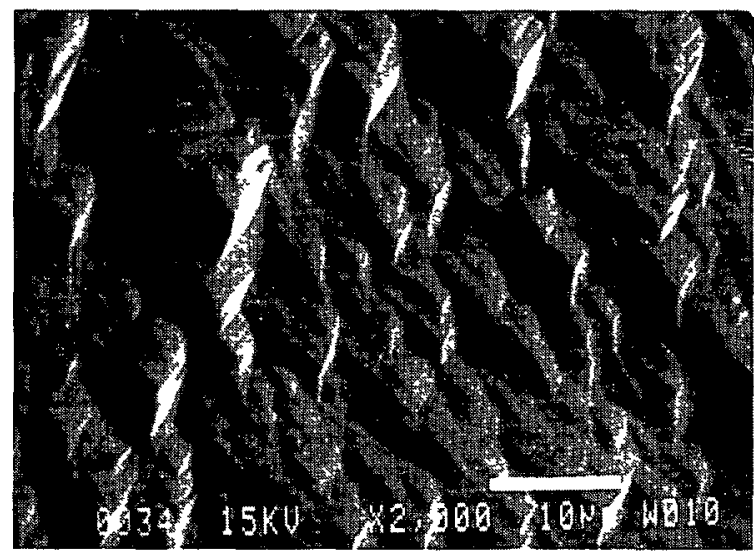

Fig. 5. - Surface texture of the $Y+45\left(\varphi_{0}=90^{\circ}, \theta_{0}=45^{\circ}\right)$ cut. Negative (a) and positive (b) faces.

\section{Confrontation of Theoretical and Experimental 2D Etching Shapes}

We will successively discuss for several cuts of quartz the theoretical and experimental results related to $2 \mathrm{D}$ surface and out-of-roundness profiles. Let us recall the basis of the sumulation of $2 \mathrm{D}$ etching shapes The etching surface profiles and out-of-roundness profiles are obtanned using the slowness polar graphs:

- For cross-sectional profiles, we use the polar plot of $L$ in the plane defined by the angles $\left(\varphi_{0}, \theta_{0}\right)$ of the considered cut. The initıal shape is circular; so starting with a cylindrical hollow, we are concerned with a concave initial profile and starting with a cylindrical crystal, we are concerned with a convex initial profile. As explained in the first part of this paper [33]. the final cross-sectional shape is determined by one type of extrema: for concave shape, the limiting facets appearing after etching are associated with maxima of $\mathbf{L}$. Conversely, for convex initial profile, the planar limiting facets are correlated to minima of $\mathbf{L}[33,43,44]$. 


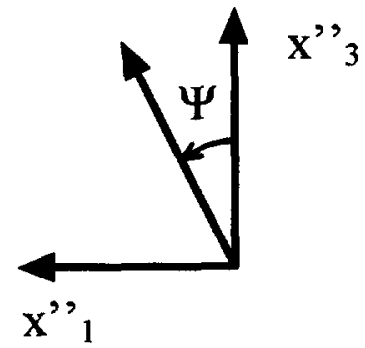

Fig. 6. - Definition of the angle $\Psi$

- The surface profiles are predicted using only a part of the polar diagram. In fact, we are concerned with profile elements whose angles $\alpha$ are in the range $\left[-\alpha_{\max },+\alpha_{\max }\right]$ with respect to the reference surface In general, the shape of profiles depends on the number and nature of extrema of the slowness associated with elements potentially present at the starting profile. However, in Section 1, we have shown that some simple shapes result from the presence of extrema in the vicinity of the orientation $\left(\varphi_{0}, \theta_{0}\right)$ of the reference surface and the nature of the extrema [33, Figs 9-10] in such a way that.

1. Fundamental concave and convex backgrounds are correlated respectively to a maximum or a minimum of slowness for the reference surface given by $\alpha=0$.

2. Profiles with alternate concave and convex shape indicate that the two kinds of extrema are present in the range $\left[-\alpha_{\max },+\alpha_{\max }\right]$.

3. Three extrema in the range $\left[-\alpha_{\max },+\alpha_{\max }\right]$ give rise to etched profiles with constant slopes.

4.1. Surface Profiles. - Since the anisotropy of chemical etching causes the formation of specific dissolution profiles depending on the cut and on the direction of traces, it is simplest to derive the theoretical profiles from a numerical simulation which starts with initial triangular profiles whose slopes are equal to $\pm \alpha_{\max }$. The influence of the initial slope is investigated, $\alpha_{\max }$ taking values respectively $15^{\circ}$ and $30^{\circ}$ In the second case, we work with a larger portion of the polar diagram of $\mathbf{L}$ The polar diagram in question corresponds to a cross-sectional section to the trace whose direction of alignment is defined by means of the angle $\psi$ (Fig. 6). In order to compare the experimental and theoretical features of dissolution profiles, we made different traces along several axes:

- For the trace which lies parallel to the $X^{\prime}$-direction $\left(\psi=90^{\circ}\right)$, the $X^{\prime}$ theoretical profile of the cut $\left(\varphi_{0}, \theta_{0}\right)$ can be derived starting with the polar plot of the plate $\left(\varphi_{0}, \theta_{0}=-90^{\circ}\right)$.

- The other trace is along the $Z^{\prime}$-axis $(\psi=0)$. Thus, it is sufficient to work with the polar plot of the $X$ cut $\left(Y\right.$ cut) for the samples defined by the angles $\left(\varphi_{0}=0, \theta_{0}\right)\left(\varphi_{0}=90^{\circ}\right.$, $\left.\theta_{0}\right)$ respectively.

- In addition, for several doubly rotated cuts, some traces are defined by the angle $\psi$ formed by $Z^{\prime \prime}$ and $X^{\prime \prime}$ axes.

4.1.1. Singly-Rotated Cuts. - We start with surface profiles of singly rotated cuts Figures 7 and 8 give theoretical and experimental traces for different etching times. The slopes of the triangular profiles are initıally equal to $\pm 15^{\circ}$, which is closed to the maximum slope observed 
a
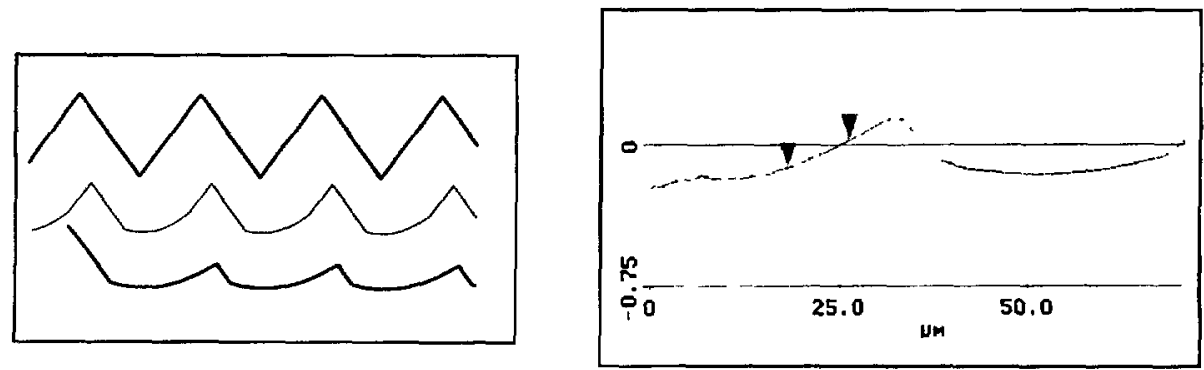

b
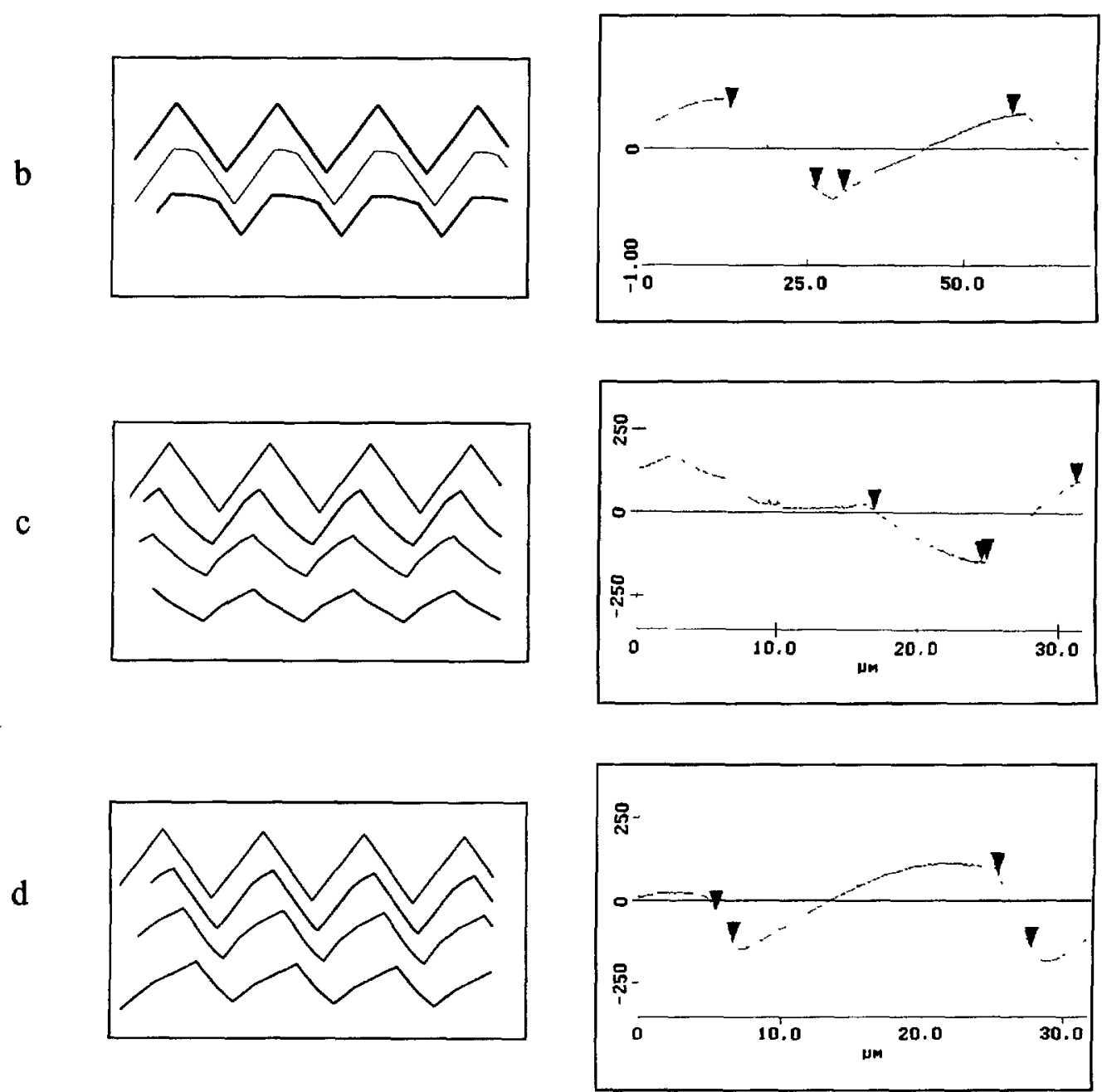

Fig 7. - Theoretical and experimental surface profiles of AT cuts. a) Case of the AT-26 cut: $X$ traces, b) Case of the AT- 26 cut. $Z^{\prime}$ traces, c) Case of the AT-50 cut $X$ traces, d) Case of the AT-50 cut: $Z^{\prime}$ traces 
a
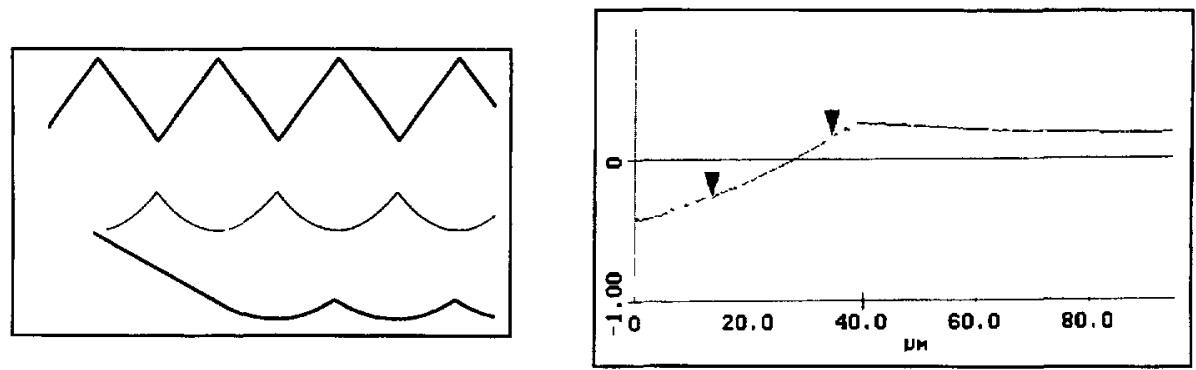

b
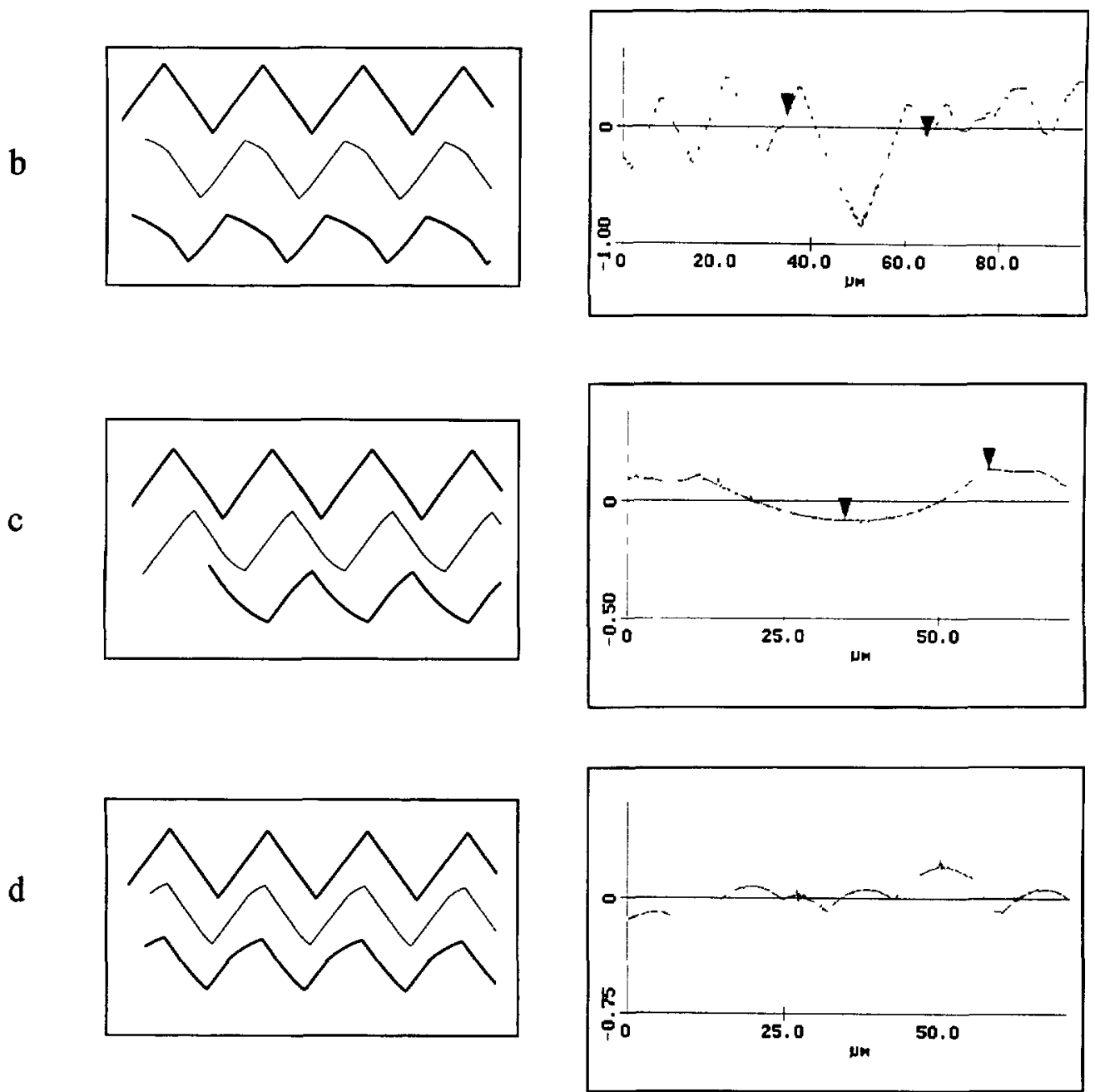

Fig 8. - Theoretical and experimental surface profiles of BT cuts a) Case of BT-49 cut $X$ traces, b) Case of BT- 49 cut: $Z^{\prime}$ traces, c) Case of BT-26 cut: $X$ traces, d) Case of BT-26 cut: $Z^{\prime}$ traces 
Table I. - Comparzson of theoretical and experimental profile shapes for AT and BT cuts.

\begin{tabular}{|c|c|c|c|c|}
\hline \multirow{2}{*}{$\begin{array}{c}\text { Cut } \\
\text { angles in } \\
\text { degrees }\end{array}$} & \multicolumn{2}{|c|}{$Y$ profile } & \multicolumn{2}{|c|}{$Z^{\prime}$ profile } \\
\hline & $\begin{array}{c}\text { Theoretıcal } \\
\text { shape }\end{array}$ & $\begin{array}{c}\text { Experimental } \\
\text { shape }\end{array}$ & $\begin{array}{c}\text { Theoretical } \\
\text { shape }\end{array}$ & $\begin{array}{c}\text { Experımental } \\
\text { shape }\end{array}$ \\
\hline $\begin{array}{c}\text { AT-26 } \\
\varphi_{0}=0 \\
\theta_{0}=26^{\circ}\end{array}$ & $\begin{array}{c}\text { Concave } \\
\text { with } \\
\text { conservation of } \\
\text { the slope with } \\
\text { angle } \alpha=12^{\circ}\end{array}$ & Concave & Convex & $\begin{array}{c}\text { Alternate } \\
\text { concave- } \\
\text { convex with a } \\
\text { convexity more } \\
\text { marked }\end{array}$ \\
\hline $\begin{array}{c}\text { AT-50 } \\
\varphi_{0}=0 \\
\theta_{0}=50^{\circ}\end{array}$ & $\begin{array}{l}\text { Alternate } \\
\text { symmetrical } \\
\text { concave- } \\
\text { convex }\end{array}$ & $\begin{array}{l}\text { Alternate } \\
\text { concave- } \\
\text { convex }\end{array}$ & $\begin{array}{l}\text { Alternate } \\
\text { convex- } \\
\text { concave }\end{array}$ & $\begin{array}{c}\text { Alternate } \\
\text { convex- } \\
\text { concave with a } \\
\text { convexity more } \\
\text { marked }\end{array}$ \\
\hline $\begin{array}{c}\text { BT-49 } \\
\varphi_{0}=0 \\
\theta_{0}=49^{\circ}\end{array}$ & $\begin{array}{l}\text { Concave } \\
\text { flat profile }\end{array}$ & $\begin{array}{l}\text { Concave } \\
\text { flat profile }\end{array}$ & $\begin{array}{l}\text { Alternate } \\
\text { concave-- } \\
\text { convex }\end{array}$ & $\begin{array}{c}\text { Rather concave } \\
\text { with } \\
\text { conservation of } \\
\text { slope } \alpha=6^{\circ}\end{array}$ \\
\hline $\begin{array}{c}\text { BT-26 } \\
\varphi_{0}=0 \\
\theta_{0}=26^{\circ}\end{array}$ & $\begin{array}{l}\text { Alternate } \\
\text { convex - } \\
\text { concave }\end{array}$ & Concave & $\begin{array}{c}\text { Alternate } \\
\text { convex- } \\
\text { concave with a } \\
\text { convexity more } \\
\text { pronounced }\end{array}$ & Convex \\
\hline
\end{tabular}

for our samples which have suffered a lapping process with grain diameter $\phi$ of about $5 \mu \mathrm{m}$. For the AT and BT cuts, we observe a good adequation between experiment and theory (Tab. I). A more detailed analysis will be performed to correlate theoretical shapes with polar diagrams (Fig. 9). The angles and magnitudes of extrema of $\mathbf{L}$ present in the range $\left[-\alpha_{\max }, \alpha_{\max }\right]$ with respect to the reference surface are summarized in Table II.

- For the AT-26 cut (Fig. 7), the X profile is concave due to the maximum of $L\left(M_{1}\right)$ and the slopes $\alpha= \pm 15^{\circ}$ disappear rapidly because they are etched more quickly (presence of minima $m_{1}$ and $m_{2}$ ); it is particularly true for the positive slope; the negative one remains much longer because the minimum of $L$ corresponding to the angle $\alpha=-12^{\circ}$ is not very marked.

The X profile for the AT-50 cut is an alternate convex-concave shape in agreement with the fact that the reference slowness is situated between a maximum $M_{1}$ and a minimum $m_{1}$. The profile remains symmetric because $M_{1}$ and $m_{1}$ lie symmetrically with respect to the orientation of the reference surface (i.e., to $\alpha=0^{\circ}$ ). 
a

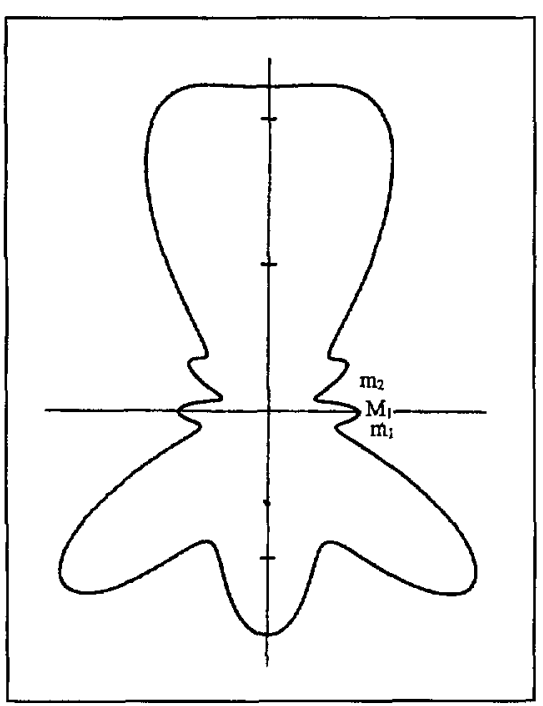

c

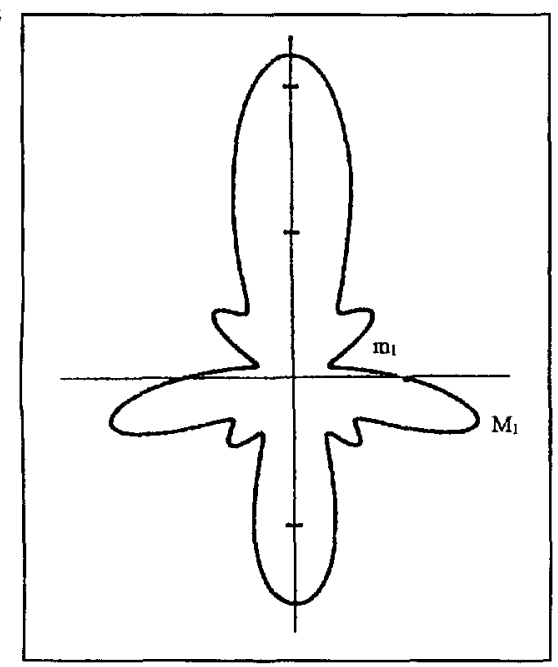

b

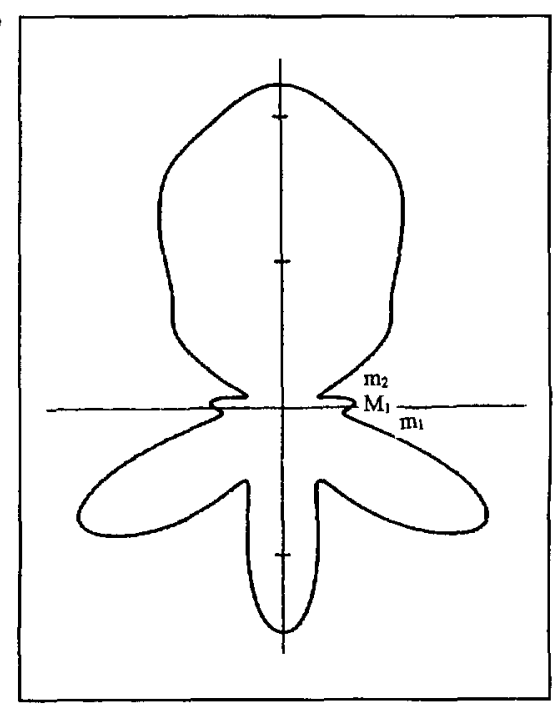

d

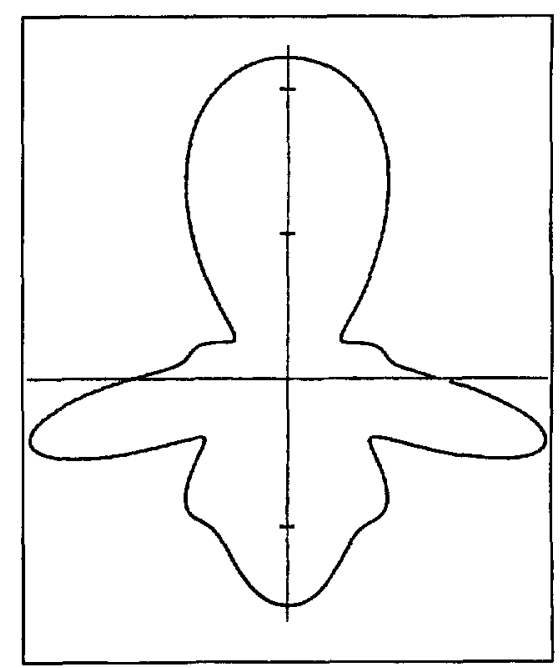

Fig. 9. - Polar plots lying in BT-64 (a), BT-40 (b), AT-40 (c) and AT-64 (d) cross-sectional plane

The theoretical $Z^{\prime}$ profile of AT-26 cut is convex and a little shifted because the minimum of $L\left(m_{1}\right)$ does not occur exactly for $\alpha=0^{\circ}$ (Tab. II). The $Z^{\prime}$ theoretical profile of AT-50 cut is a symmetrical alternate convex-convave profile in accord with the fact that the maximum and minimum $\left(M_{1}^{\prime}, m_{1}^{\prime}\right)$ of slowness are located at the same angular distance from the reference surface slowness.

- Let us analyze the surface profiles of various singly-rotated cuts as displayed in Figure 8. The BT-49 profile along the $X$-direction is very particular. When we analyze such an experimental trace. we simply conclude that a minimum in $L$ exists for $\alpha=0$. This constitutes a false interpretation! We observe on the theoretical profile that the convex intersections $I_{\mathrm{c}}$ 
Table II. - Angles and magnitudes of extrema of $L$ near the reference surface for $A T$ and $B T$ cuts.

\begin{tabular}{|c|c|c|c|c|c|c|}
\hline $\begin{array}{c}\text { Cut } \\
\text { angles in } \\
\text { degrees }\end{array}$ & \multicolumn{3}{|c|}{$\begin{array}{l}\text { Polar plot for } X \text { profile } \\
\text { angles and magnitudes of } \\
\text { extrema of } L \text { in the range } \\
\qquad\left[-20^{\circ}, 20^{\circ}\right]\end{array}$} & \multicolumn{3}{|c|}{$\begin{array}{l}\text { Polar plot for } Z^{\prime} \text { profile } \\
\text { angles and magnitudes of } \\
\text { extrema of } L \text { in the range } \\
\qquad\left[-20^{\circ}, 20^{\circ}\right]\end{array}$} \\
\hline $\begin{array}{c}\text { AT-26 } \\
\left\{\begin{array}{l}\varphi_{0}=0^{\circ} \\
\theta_{0}=26^{\circ}\end{array}\right.\end{array}$ & $\begin{array}{l}\operatorname{minımum} m_{1} \\
\operatorname{maximum} M_{1} \\
\text { mınimum } m_{2}\end{array}$ & $\begin{array}{l}L=22.5 \\
L=29 \\
L=15.5\end{array}$ & $\begin{array}{l}\alpha=-12^{\circ} \\
\alpha=0 \\
\alpha=17^{\circ}\end{array}$ & $\begin{array}{l}\operatorname{minımum} m_{1} \\
\text { maximum } M_{1}\end{array}$ & $\begin{array}{l}L=28 \\
L=34\end{array}$ & $\begin{array}{l}\alpha=1^{\circ} \\
\alpha=12^{\circ}\end{array}$ \\
\hline $\begin{array}{c}\text { AT }-50 \\
\left\{\begin{array}{c}\varphi_{0}=0^{\circ} \\
\theta_{0}=50^{\circ}\end{array}\right.\end{array}$ & $\begin{array}{l}\operatorname{minimum} m_{1} \\
\text { maxımum } M_{1} \\
\text { minimum } m_{2}\end{array}$ & $\begin{array}{l}L=194 \\
L=23 \\
L=12\end{array}$ & $\begin{array}{l}\alpha=-6^{\circ} \\
\alpha=5^{\circ} \\
\alpha=20^{\circ}\end{array}$ & $\begin{array}{l}\operatorname{maximum} M_{1} \\
\text { minimum } m_{2}\end{array}$ & $\begin{array}{l}L=34 \\
L=17\end{array}$ & $\begin{array}{l}\alpha=-12^{\circ} \\
\alpha=8^{\circ}\end{array}$ \\
\hline $\begin{array}{c}\text { BT- } 49 \\
\left\{\begin{array}{l}\varphi_{0}=0^{\circ} \\
\theta_{0}=-49^{\circ}\end{array}\right.\end{array}$ & $\begin{array}{l}\operatorname{maximum} M_{1} \\
\text { minimum } m_{1}\end{array}$ & $\begin{array}{l}L=61 \\
L=12\end{array}$ & $\begin{array}{l}\alpha=-14^{\circ} \\
\alpha=20^{\circ}\end{array}$ & $\begin{array}{l}\operatorname{maximum} M_{2} \\
\text { minimum } m_{3} \\
\text { maxımum } M_{3}\end{array}$ & $\begin{array}{l}L=53 \\
L=32 \\
L=34\end{array}$ & $\begin{array}{l}\alpha=-19^{\circ} \\
\alpha=5^{\circ} \\
\alpha=14^{\circ}\end{array}$ \\
\hline $\begin{array}{c}\text { BT- } 26 \\
\left\{\begin{array}{l}\varphi_{0}=0^{\circ} \\
\theta_{0}=-26^{\circ}\end{array}\right.\end{array}$ & $\begin{array}{r}\text { No maxim } \\
\text { the } \mathrm{cc}\end{array}$ & idered ra & num in & $\begin{array}{l}\operatorname{minimum} m_{\mathbf{4}} \\
\operatorname{maximum} M_{2}\end{array}$ & $\begin{array}{l}L=49 \\
L=53\end{array}$ & $\begin{array}{l}\alpha=-4^{\circ} \\
\alpha=6^{\circ}\end{array}$ \\
\hline
\end{tabular}

move on the right direction. This is sufficient to conclude that the symmetry of the profile is an artifact, because if a minimum of slowness occurs for the surface reference intersection, $I_{c}$ will move along a vertical line (compare with Fig. 10a on Part I of this paper [33]).

The $\mathrm{BT}-26 \mathrm{X}$ profile constitutes also a special case. There is no extremum in the range $\left[-15^{\circ}, 15^{\circ}\right]$, but we observe on the polar plot a curvature which occurs in the considered range, and the inflexion point is closed to $\alpha=0^{\circ}$. So, the behavior is equivalent to that resulting from the presence of two extrema in the $\left[-\alpha_{\max }, \alpha_{\max }\right]$ range. In fact, as compared with the experimental profile which seems rather concave, the change of curvature of the polar plot seems too accentuated. However, the angular position of extrema of $L$ in the polar plot can be in fair agreement with experiment.

Now, we turn attention on the $Z^{\prime}$ profile of BT-49 cut. The theoretical one is alternate concave-convex with a predominance of convex shape. A minimum of the slowness $m_{3}$ is present near the reference slowness $a=0^{\circ}$, while maxuma $M_{2}$ and $M_{3}$ have more distant angular positions (Fig. 10). The experimental profile is characterized by the persistence of constant slopes in the process of etching which indicates that three extrema are present in the range $\left[-15^{\circ}, 15^{\circ}\right]$. The theoretical $Z^{\prime}$ profile of BT-26 cut is constituted of alternate convexconcave shape in correlation with the maximum $M_{2}$ and minimum $m_{4}$ lying respectıvely at $\alpha=-10^{\circ}$ and $\alpha=+4^{\circ}$. The experimental profile indicates that we have an angular shift of the minimum $m_{6}$.

4.1.2. Doubly-Rotated Cuts. - Let us continue with the doubly-rotated cuts $\left(\varphi_{0}=90^{\circ}, \theta_{0}\right)$. In Figures 12 and 13, the theoretical profiles have now initial slopes of $\pm 30^{\circ}$. From the A.F.M. micrographs (Fig. 11) we observe that the two faces do not have at all the same dissolution figures. For the two cuts $Y+40\left(\theta_{0}=40^{\circ}\right)$ and $Y^{-}+30\left(\theta_{0}=30^{\circ}\right)$, the etching generates flat 


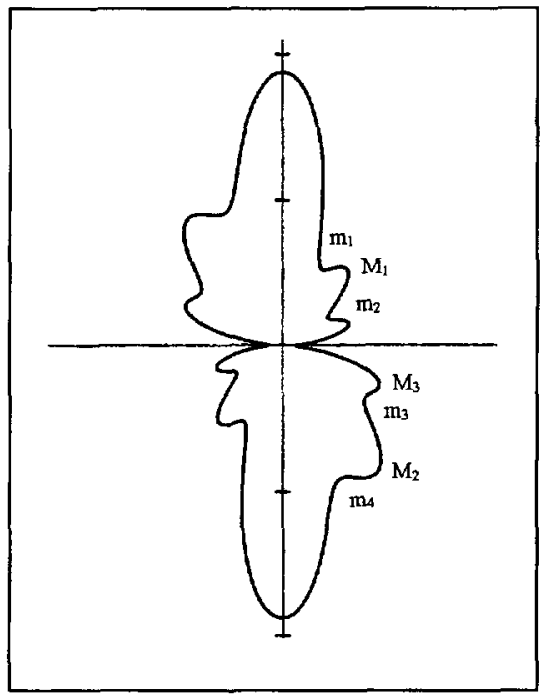

Fig. 10. - Polar plot of the dissolution slowness in the plane defined by $\left(\theta_{0}=90^{\circ}\right)$.

Table III. - Experimental slopes of profiles after etching.

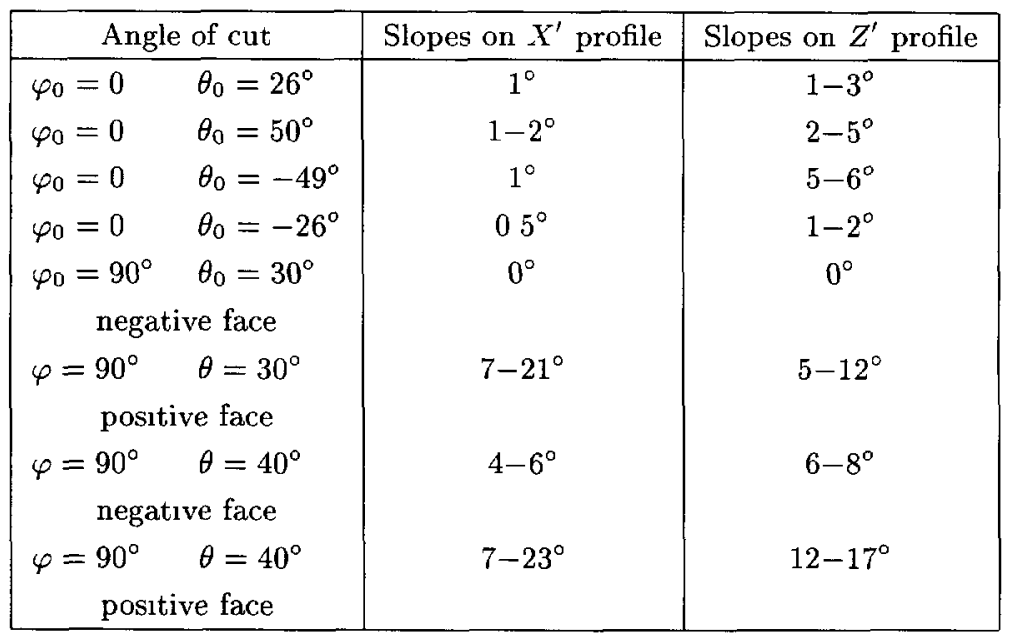

surfaces and large dissolution figures on the negative face. On the contrary, we have marked shapes and high slopes (Tab. III) on the positive face. Moreover, the dissolution figures are composed of some limiting rather flat facets. The major features of $\psi=0^{\circ}$ and $\psi=90^{\circ}$ profilometry traces made along $Y$ and $Z^{\prime}$ directions are summarized in Table IV.

- Let us turn our attention to the $Y+40$ cut and to its predicted profiles (Fig. 12). The $Y$ profile appears to be convex for the negative face due to the marked minimum $m_{5}$ of $L$ which is a little shifted with respect to $\alpha=0^{\circ}$. It becomes alternate convex-concave for the positive face in agreement with the presence of two extrema in the $\alpha$ range investigated here $\left(m_{6}, M_{6}\right)$.

For the $Y$ profile of $Y+30$ cut (Fig. 12) and for the negative face, the convexity is due to the marked minimum $m_{4}$ on the polar plot for negative slopes. For positive slopes, we remark 

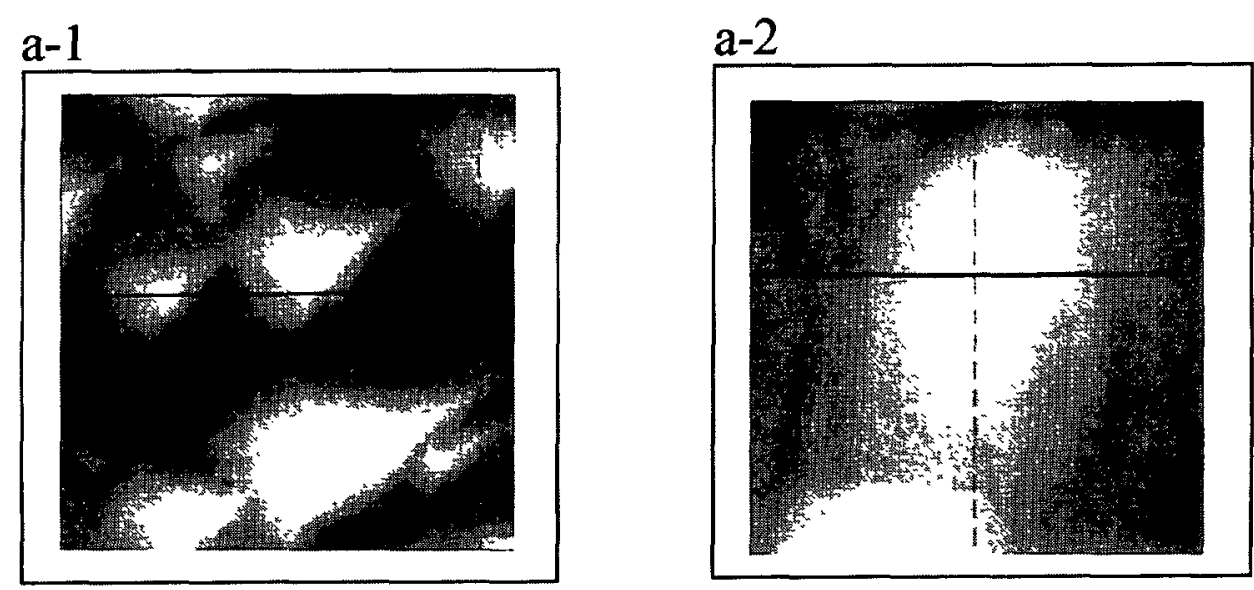

b-1

Fig 11. - A.F.M micrographs of $Y+40\left(\varphi_{0}=90^{\circ}, \theta_{0}=40^{\circ}\right)(\mathrm{a})$ and $Y+30\left(\varphi_{0}=90^{\circ}, \theta_{0}=30^{\circ}\right)$ (b) cuts Case of positive face ( $a .1$ and $b 1$ ) and negative one (a 2)

an inflexion of the polar plot but it appears for an angle which deviates from more than $30^{\circ}$ from the reference slowness. So, no extremum occurs for positive slopes and they do not vary. On the positive face, the $Y+30$ cut has a $Y$ profile rather concave due to the presence of the marked maximum $M_{5}$ of the slowness; so the convexity due to the minimum $m_{3}$ disappears after a given time of etching.

- The $Z^{\prime}$ profiles (Fig. 13) are analyzed with the Y polar plot (Fig. 14). For the positive $Y+40$ cut face, the concavity of the profile is explained by the presence of maximum $M_{3}$ for $36^{\circ}\left(\alpha=-4^{\circ}\right)$. But we observe, as expected, that this concavity is not marked.

Concerning the $Y+30$ cut, the positive face presents a concave shape for positive slopes and a constant slope of $-30^{\circ}$ for the other part of the triangular profile. Analyzing the $Y$ polar plot, we conclude that the etching profile must be a symmetrical alternate convave-convex profile because the reference slowness is situated just between a maximum $\left(M_{3}\right)$ and a minimum $\left(m_{2}\right)$. In fact. for the last two profiles the horizontal components of the propagation vector are in the 
Table IV. - Comparison of theoretucal and experimental profile shapes for $Y$ rotated cuts.

\begin{tabular}{|c|c|c|c|c|}
\hline \multirow{2}{*}{$\begin{array}{c}\text { Cut } \\
\text { angles in } \\
\text { degrees }\end{array}$} & \multicolumn{2}{|c|}{$X$ profile } & \multicolumn{2}{|c|}{$Z^{\prime}$ profile } \\
\hline & $\begin{array}{c}\text { Theoretical } \\
\text { shape }\end{array}$ & $\begin{array}{c}\text { Experimental } \\
\text { shape }\end{array}$ & $\begin{array}{c}\text { Theoretical } \\
\text { shape }\end{array}$ & $\begin{array}{c}\text { Experimental } \\
\text { shape }\end{array}$ \\
\hline $\begin{array}{c}Y+40 \\
\left\{\begin{array}{c}\varphi_{0}=90^{\circ} \\
\theta_{0}=40^{\circ}\end{array}\right. \\
\text { positive face }\end{array}$ & $\begin{array}{c}\text { Alternate } \\
\text { symmetrical } \\
\text { concave-- } \\
\text { convex profile }\end{array}$ & $\begin{array}{c}\text { Alternate } \\
\text { concave- } \\
\text { convex with a } \\
\text { more marked } \\
\text { convex part }\end{array}$ & $\begin{array}{c}\text { Rather concave } \\
\text { with constant } \\
\text { slopes }\end{array}$ & Constant slopes \\
\hline $\begin{array}{c}Y+40 \\
\left\{\begin{array}{c}\varphi_{0}=90^{\circ} \\
\theta_{0}=40^{\circ}\end{array}\right. \\
\text { negative face }\end{array}$ & Rather convex & Convex & Constant slopes & Rather convex \\
\hline $\begin{array}{c}Y+30 \\
\left\{\begin{array}{l}\varphi_{0}=90^{\circ} \\
\theta_{0}=30^{\circ}\end{array}\right. \\
\text { positive face }\end{array}$ & $\begin{array}{c}\text { Alternate } \\
\text { convex- } \\
\text { concave profile } \\
\text { with a more } \\
\text { marked } \\
\text { concave part }\end{array}$ & $\begin{array}{l}\text { Alternate } \\
\text { convex- } \\
\text { concave } \\
\text { profile }\end{array}$ & $\begin{array}{c}\text { Alternate } \\
\text { concave- } \\
\text { convex profile }\end{array}$ & $\begin{array}{l}\text { Alternate } \\
\text { concave- } \\
\text { convex } \\
\text { profile }\end{array}$ \\
\hline $\begin{array}{c}Y+30 \\
\left\{\begin{array}{c}\varphi_{0}=90^{\circ} \\
\theta_{0}=30^{\circ}\end{array}\right. \\
\text { negative face }\end{array}$ & $\begin{array}{l}\text { Rather convex } \\
\text { profile and } \\
\text { constant slope } \\
\text { for positive } \\
\text { slope }\end{array}$ & & $\begin{array}{c}\text { Alternate } \\
\text { concave- } \\
\text { convex profile }\end{array}$ & \\
\hline
\end{tabular}

same direction for positive and negative slopes; so, a part of the concave (for $Y+40$ cut) and the convex (for $Y+30 \mathrm{cut}$ ) intersection of profile is lost. We can easily verify this assumption by following the change in shape of surface profile involving elements of smaller slopes. We can see that, for slopes of $\alpha= \pm 15^{\circ}$ (F1g 15), the $Y+40$ negative face presents a rather convex $Z^{\prime}$ profile. This shape is due to the minimum $m_{1}$ which occurs for $\alpha=10^{\circ}$. The other slope of the initial profile does not be modified because no extremum occurs in the considered range of negative slopes. The $Z^{\prime}$ profile of the $Y+30$ negative face is composed of a concave part and the conservation of negative slope. The analysis with the polar plot is not easy because the change in shape is not only governed by extrema. Here the change in curvature near the reference slowness has a great influence on the change in shape. The importance of the numerical simulation is conveniently illustrated by these few examples. Effectively, when several successive extrema are present in the range of positive slopes or of negative slopes, no simple model allows to obtain the final etching shape.

Experimentally (Fig. 16), the $Y$ profile becomes rapidly very flat, so we cannot draw any conclusion on the adequation of angular positions of extrema. 
$\mathbf{a}$

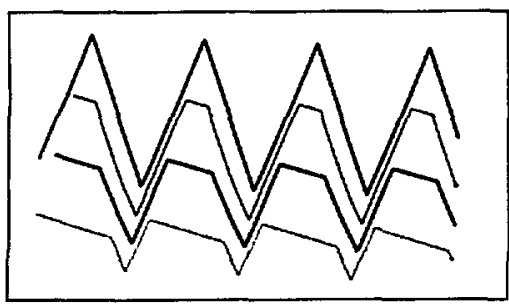

c

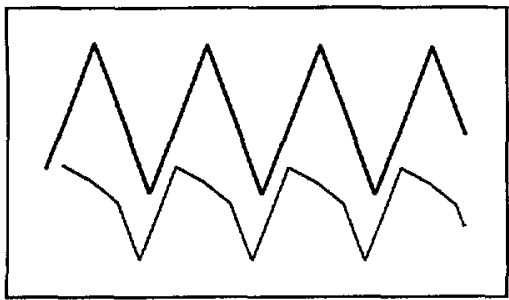

e

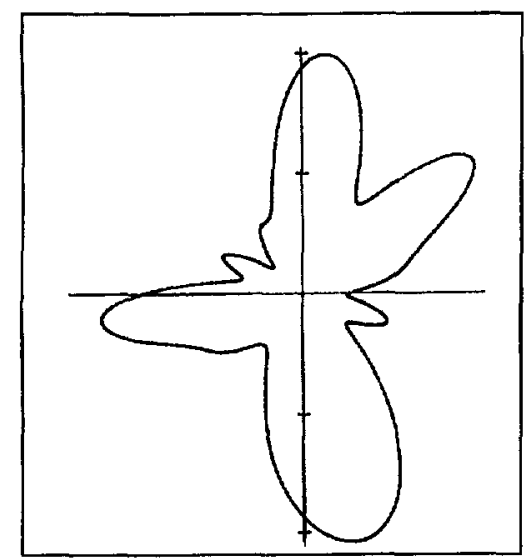

b

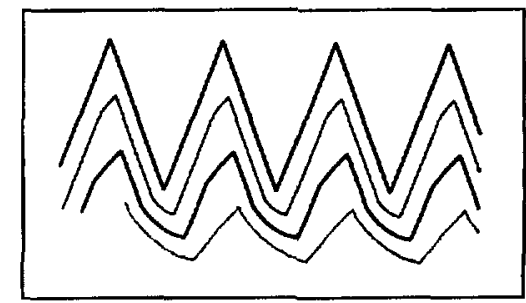

d

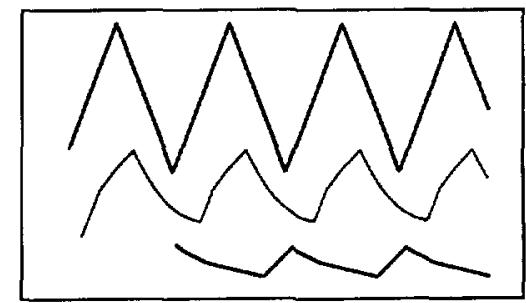

f

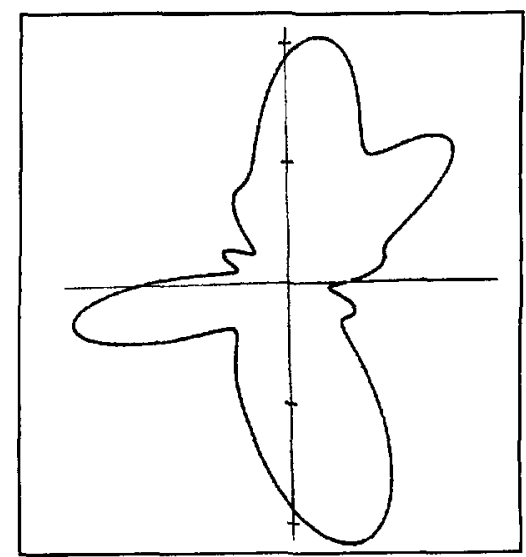

Fig 12. - Theoretical surface profiles along $Y$-axis. Case of the negative (a) and positive (b) face of the $Y+40 \mathrm{cut}\left(\varphi_{0}=90^{\circ}, \theta_{0}=40^{\circ}\right)$ Case of the negative (c) and positive (d) face of the $Y+30$ cut $\left(\varphi_{0}=90^{\circ}, \theta_{0}=30^{\circ}\right)$ Polar plots corresponding to the $Y$ profiles for $Y+40$ cut (e) and $Y+30$ cut (f).

In conclusion, we observe some disagreements between theoretical and experimental $Y$ and $Z^{\prime}$ profiles. This observation is not surprising because the dissolution figures are not preferentially aligned along $Y$ - or $Z^{\prime}$-axes. In this condition, it seems better to derive new simulations for the apparent direction of alignment of experimental dissolution figures. Figures 17 to 20 give experimental and theoretical traces along and perpendicular to the direction of the dissolution patterns. We repeat the simulation with two initial triangular slopes $\alpha_{\max }= \pm 15^{\circ}$ and $\alpha_{\max }= \pm 30^{\circ}$. All the predicted profiles are derived for the same etching time. We immediately observe that the shape of traces are dependent on the slopes initially present on the sample in close accord with experiments For the positive faces, the simulation with $\alpha_{\max }= \pm 30^{\circ}$ gives results close to experiments: in particular experimental values of slope 


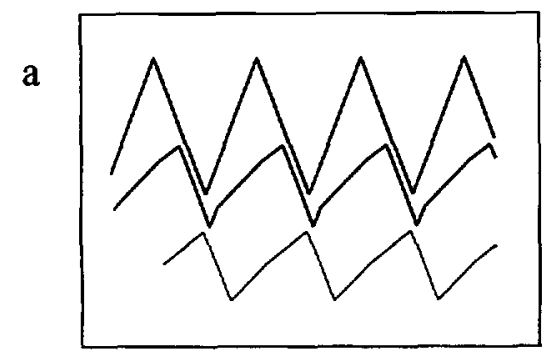

b

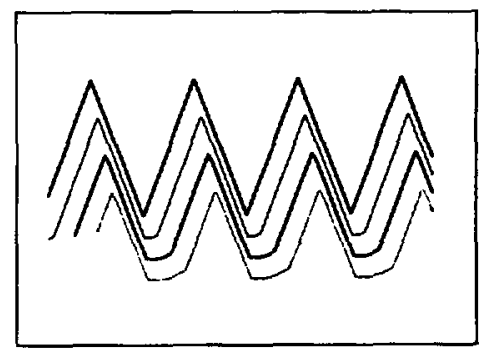

c

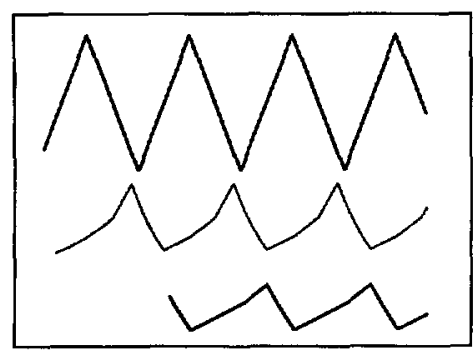

d

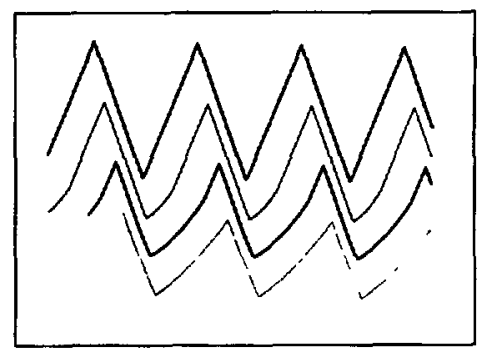

Fig. 13 - Theoretical surface profiles along $Z^{\prime}$-axis Case of the negative (a) and positive (b) face of the $Y+40$ cut Case of the negative (c) and positive (d) face of the $Y+30$ cut.

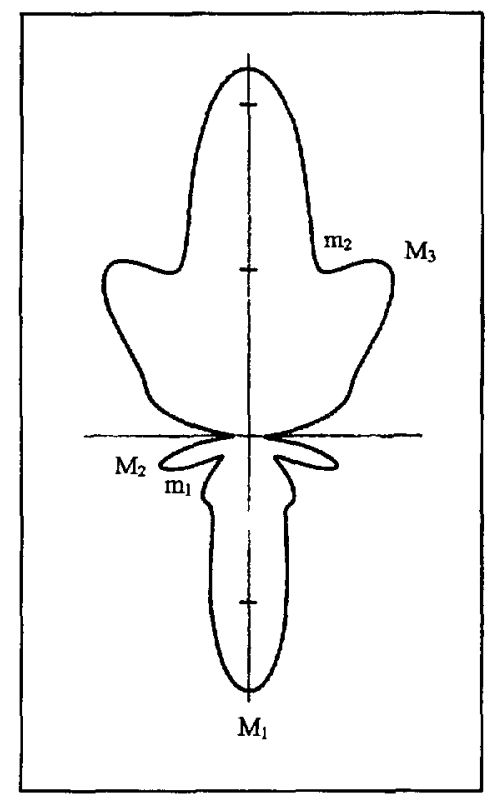

Fig. 14. - Polar plot of the dissolution slowness in the $Y$-plane.

agree well with the predicted values (Tab. VI). The shapes of theoretical profiles are easily explained in terms of the polar plots.

- For example, let us analyze the positive face of the $Y+40$ cut (Fig. 18). We observe for 
Table V. - Angles and magnatudes of extrema of the slowness near the reference surface for $Y$ rotated cuts

\begin{tabular}{|c|c|c|c|c|c|c|}
\hline $\begin{array}{c}\text { Cut } \\
\text { angles in } \\
\text { degrees }\end{array}$ & \multicolumn{3}{|c|}{$\begin{array}{l}\text { Polar plot for } Y \text { profile } \\
\text { angles and magnitudes of } \\
\text { extrema of } L \text { in the range } \\
\qquad\left[-30^{\circ}, 30^{\circ}\right]\end{array}$} & \multicolumn{3}{|c|}{$\begin{array}{l}\text { Polar plot for } Z^{\prime} \text { profile } \\
\text { angles and magnitudes of } \\
\text { extrema of } L \text { in the range } \\
\qquad\left[-30^{\circ}, 30^{\circ}\right]\end{array}$} \\
\hline $\begin{array}{c}Y+40 \\
\left\{\begin{array}{l}\varphi_{0}=90^{\circ} \\
\theta_{0}=40^{\circ}\end{array}\right. \\
\text { positive face }\end{array}$ & $\begin{array}{l}\operatorname{maximum} M_{1} \\
\text { minimum } m_{1} \\
\text { maximum } M_{2}\end{array}$ & $\begin{array}{l}L=34 \\
L=24 \\
L=80\end{array}$ & $\begin{array}{l}\alpha=-27^{\circ} \\
\alpha=-15^{\circ} \\
\alpha=7^{\circ}\end{array}$ & $\begin{array}{l}\text { minımum } m_{2} \\
\text { maximum } M_{3}\end{array}$ & $\begin{array}{l}L=53 \\
L=64\end{array}$ & $\begin{array}{l}\alpha=-18^{\circ} \\
\alpha=-4^{\circ}\end{array}$ \\
\hline $\begin{array}{c}Y+40 \\
\left\{\begin{array}{l}\varphi_{0}=90^{\circ} \\
\theta_{0}=40^{\circ}\end{array}\right. \\
\text { negative face }\end{array}$ & $\begin{array}{l}\operatorname{maximum} M_{3} \\
\text { minımum } m_{2}\end{array}$ & $\begin{array}{l}L=35 \\
L=17\end{array}$ & $\begin{array}{l}\alpha=-21^{\circ} \\
\alpha=-4^{\circ}\end{array}$ & $\begin{array}{l}\operatorname{minimum} m_{1} \\
\operatorname{maxımum} M_{2}\end{array}$ & $\begin{array}{l}L=95 \\
L=26\end{array}$ & $\begin{array}{l}\alpha=10^{\circ} \\
\alpha=29^{\circ}\end{array}$ \\
\hline $\begin{array}{c}\mathrm{Y}+30 \\
\left\{\begin{array}{l}\varphi_{0}=90^{\circ} \\
\theta_{0}=30^{\circ}\end{array}\right. \\
\text { positive face }\end{array}$ & $\begin{array}{l}\operatorname{maximum} M_{4} \\
\text { mınimum } m_{3} \\
\text { maximum } M_{5}\end{array}$ & $\begin{array}{l}L=29 \\
L=21 \\
L=87\end{array}$ & $\begin{array}{l}\alpha=-27^{\circ} \\
\alpha=-15^{\circ} \\
\alpha=10^{\circ}\end{array}$ & $\begin{array}{l}\operatorname{minimum} m_{2} \\
\text { maximum } M_{3}\end{array}$ & $\begin{array}{l}L=53 \\
L=64\end{array}$ & $\begin{array}{l}\alpha=-8^{\circ} \\
\alpha=6^{\circ}\end{array}$ \\
\hline $\begin{array}{c}Y+30 \\
\left\{\begin{array}{l}\varphi_{0}=90^{\circ} \\
\theta_{0}=30^{\circ}\end{array}\right. \\
\text { negative face }\end{array}$ & $\begin{array}{l}\operatorname{maximum} M_{6} \\
\text { minimum } m_{4}\end{array}$ & $\begin{array}{l}L=29 \\
L=16\end{array}$ & $\begin{array}{l}\alpha=-27^{\circ} \\
\alpha=-9^{\circ}\end{array}$ & $\begin{array}{l}\operatorname{maxımum} M_{1} \\
\text { minımum } m_{1}\end{array}$ & $\begin{array}{l}L=77 \\
L=95\end{array}$ & $\begin{array}{l}\alpha=-30^{\circ} \\
\alpha=20^{\circ}\end{array}$ \\
\hline
\end{tabular}

Table VI. - Experimental slopes of profiles after etching.

\begin{tabular}{|c|c||c|c|}
\hline $\begin{array}{c}\text { Angle of cut } \\
\left(\varphi_{0}, \theta_{0}\right)\end{array}$ & Slopes on profile & $\begin{array}{c}\text { Angle of cut } \\
\left(\varphi_{0}, \theta_{0}\right) \\
\text { Direction of } \\
\text { pirection of } \\
\text { profile } \psi\end{array}$ & Slopes on profile $\psi$ \\
\hline$\varphi_{0}=90^{\circ} \theta_{0}=30^{\circ}$ & $15^{\circ}$ & $\varphi_{0}=90^{\circ} \theta_{0}=40^{\circ}$ & $15^{\circ}$ \\
positive face & $-4^{\circ}$ & positive face & $-10^{\circ}$ \\
$\psi=32^{\circ}$ & & $\psi=35^{\circ}$ & \\
\hline$\varphi_{0}=90^{\circ} \theta_{0}=30^{\circ}$ & $20^{\circ}$ & $\varphi_{0}=90^{\circ} \theta_{0}=40^{\circ}$ & $16^{\circ}$ \\
positive face & $-20^{\circ}$ & positive face & $-28^{\circ}$ \\
$\psi=-58^{\circ}$ & & $\psi=-55^{\circ}$ & \\
\hline$\varphi_{0}=90^{\circ} \theta_{0}=30^{\circ}$ & $3^{\circ}$ & $\varphi_{0}=90^{\circ} \theta_{0}=40^{\circ}$ & $4^{\circ}$ \\
negative face & $-3^{\circ}$ & negative face & $-10^{\circ}$ \\
$\psi=54^{\circ}$ & & $\psi=40^{\circ}$ & \\
\hline$\varphi_{0}=90^{\circ} \theta_{0}=30^{\circ}$ & & $\varphi_{0}=90^{\circ} \theta_{0}=40^{\circ}$ & $14^{\circ}$ \\
negative face & Weak slopes & negative face & $-6^{\circ}$ \\
$\psi=-36^{\circ}$ & & $\psi=-50^{\circ}$ & \\
\hline
\end{tabular}


a

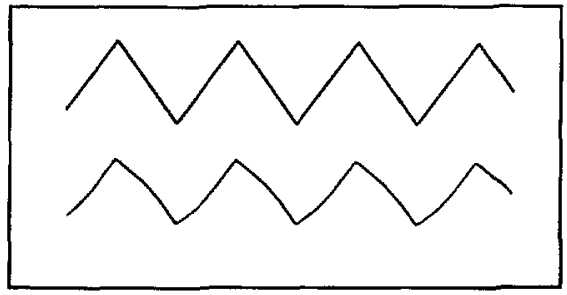

b

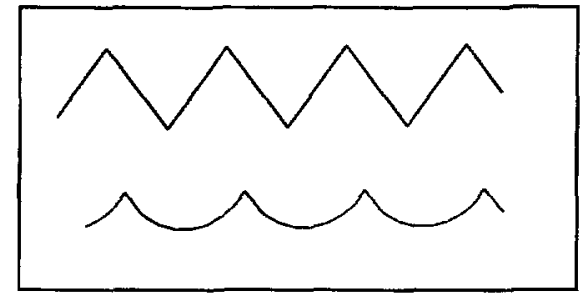

Fig $15-Z^{\prime}$ profiles of $Y+40(\mathrm{a})$ and $Y+30(\mathrm{~b})$ cuts Case of small initial slopes $\alpha_{\max }= \pm 15^{\circ}$

initial slope of $\pm 15^{\circ}$ a concave profile for $\psi=35^{\circ}$ or $\psi=-55^{\circ}$. However, the reference slowness does not correspond to a maximum of $L$ That is exactly the same artefact as in Figure 8a. Concerning the profile with initial slopes of $\pm 30^{\circ}$, the extrema of $L$ are situated in the range $\left[-30^{\circ}, 30^{\circ}\right]$ and the changes of shape are easily explained. The alternance of concavity and convexity is due to the presence of a maximum and a minimum around the slowness reference. Concerning the negative face (Fig. 17), the profile for $\psi=40^{\circ}$ is convex for positive slopes due to the minimum $m_{1}$. This minimum is really marked, so for initial higher slopes, it induces the formation of a limiting facet rather than of a concave background. The negative slope is unmodified for the least slopped profile because there is no extrema for $-15^{\circ}<\alpha<0^{\circ}$. On the contrary, the maximum $M_{1}$ is included in the range $-30^{\circ}<\alpha<0^{\circ}$ and induces a limiting facet for large initial slopes. For $\psi=-50^{\circ}$, the initıal flat profile does not change during etching because the polar diagram is very flat around the reference slowness. For such initial large slopes we note a concavity due to the slight minimum $m_{1}$.

- Let us analyze the changes of profile in the $Y+30$ cut (Figs. 19, 20). The profile $\psi=32^{\circ}$ is concave-convex because a maximum $M_{1}$ (for positive slopes) and a minimum $m_{1}$ (for negative slopes) are included in the range $\left[-30^{\circ}, 30^{\circ}\right]$. For lower initial slopes we find again an alternate profile, but as the extrema are not situated in the range $\left[-15^{\circ}, 15^{\circ}\right]$ we only see here the effect of curvatures associated with maximum and minimum. Concerning the $\psi=-58^{\circ}$ profile, the concave shape for lower slopes is an artefact it is the same situation as for the positive face of $Y+40$ in the direction $\psi=35^{\circ}$ (Fig. 18). For the initial $30^{\circ}$ slope, we obtain a concave shape due to the curvature of the polar plot induced by the maximum $M_{1}$. The convex shape for negative slope is caused by the minimum $m_{1}$ at angle of 20 degrees. For the negative face, the changes in the initial triangular profile with $\alpha_{\max }= \pm 15^{\circ}$ are similar for $\psi=54^{\circ}$ or $\psi=-36^{\circ}$. The reference slowness is situated between minimum $m_{1}$ and maximum $M_{1}$ in the considered range. For high slopes, the interpretation for both profiles is similar. We have two extrema of $L$ in the range $\left[-30^{\circ}, 0\right]$ for $\psi=54^{\circ}$, and in the range $\left[0,30^{\circ}\right]$ for $\psi=-36^{\circ}$. In these cases again, the analysis is complex and we see here all the interest of the simulation.

Figure 19, we observe deviations between theoretical and experimental profiles which indicate that we have to adjust the polar plot for $\varphi_{0}=90^{\circ}$ and $\theta_{0}$ around $30^{\circ}$. 

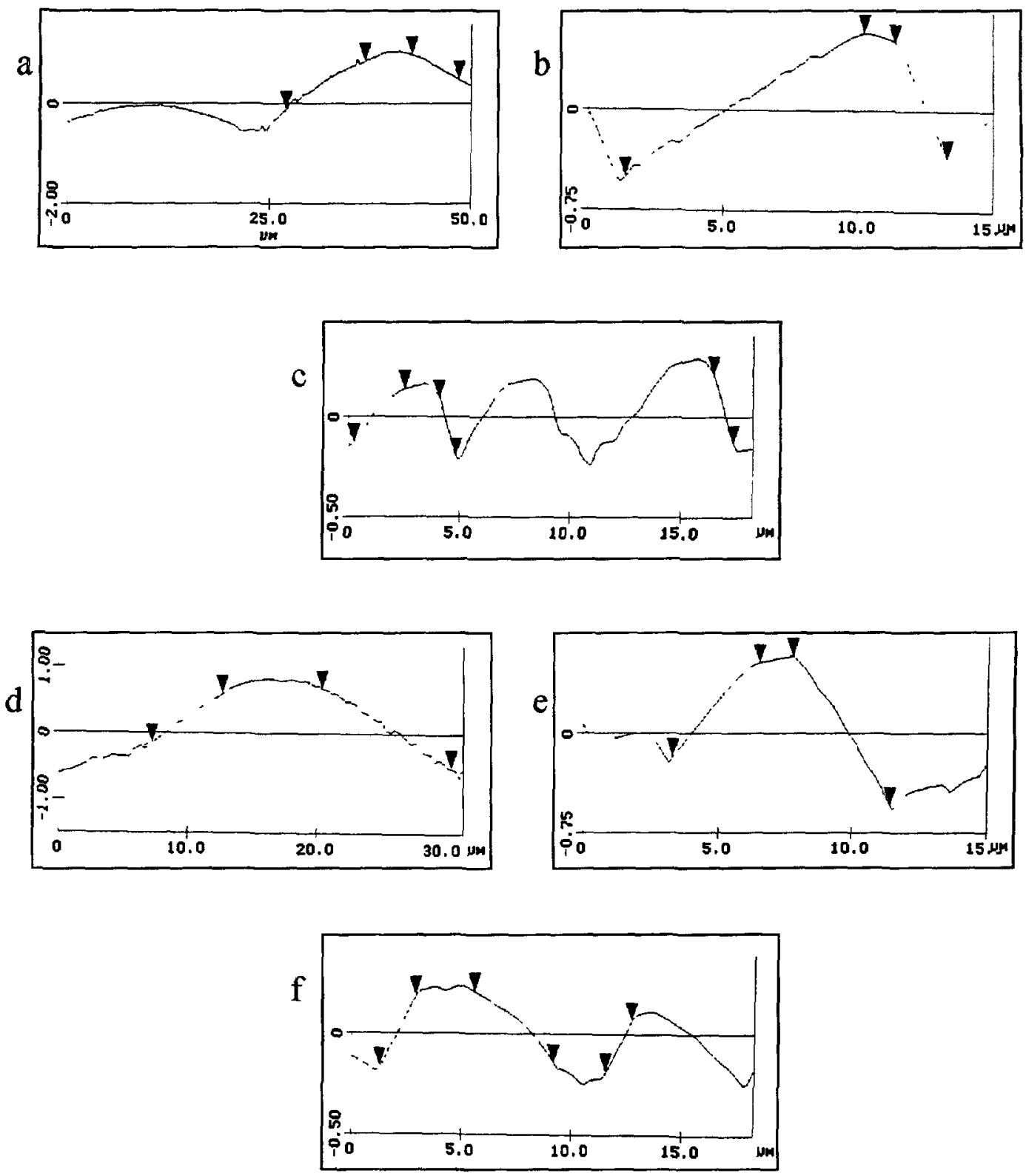

Fig 16 - Experimental surface profiles along $Y$-axis (a) $Y+40$ cut negative face, (b) $Y+40$ cut positive face, (c) $Y+30$ cut positive face Experimental surface profiles along $Z^{\prime}$-axis: (d) $Y+40$ cut negative face, (e) $Y+40$ cut positive face, (f) $Y+30$ cut positive face

4.2. Cross-Sectional Out-of-Roundness Profiles $[45,46]$. - Several etched out-ofroundness profiles related to deeply etched singly- or doubly-rotated cuts are shown in Figures 21 to 23 . All the experimental out-of-roundness exhibit successive minima and maxima. Moreover, AT and BT dissolution profiles satisfy to the two-fold symmetry along $X$-axis. Here, 


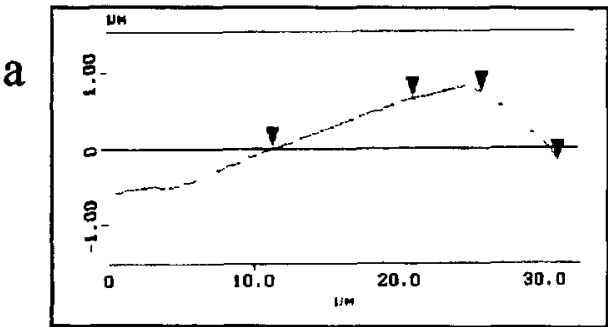

b
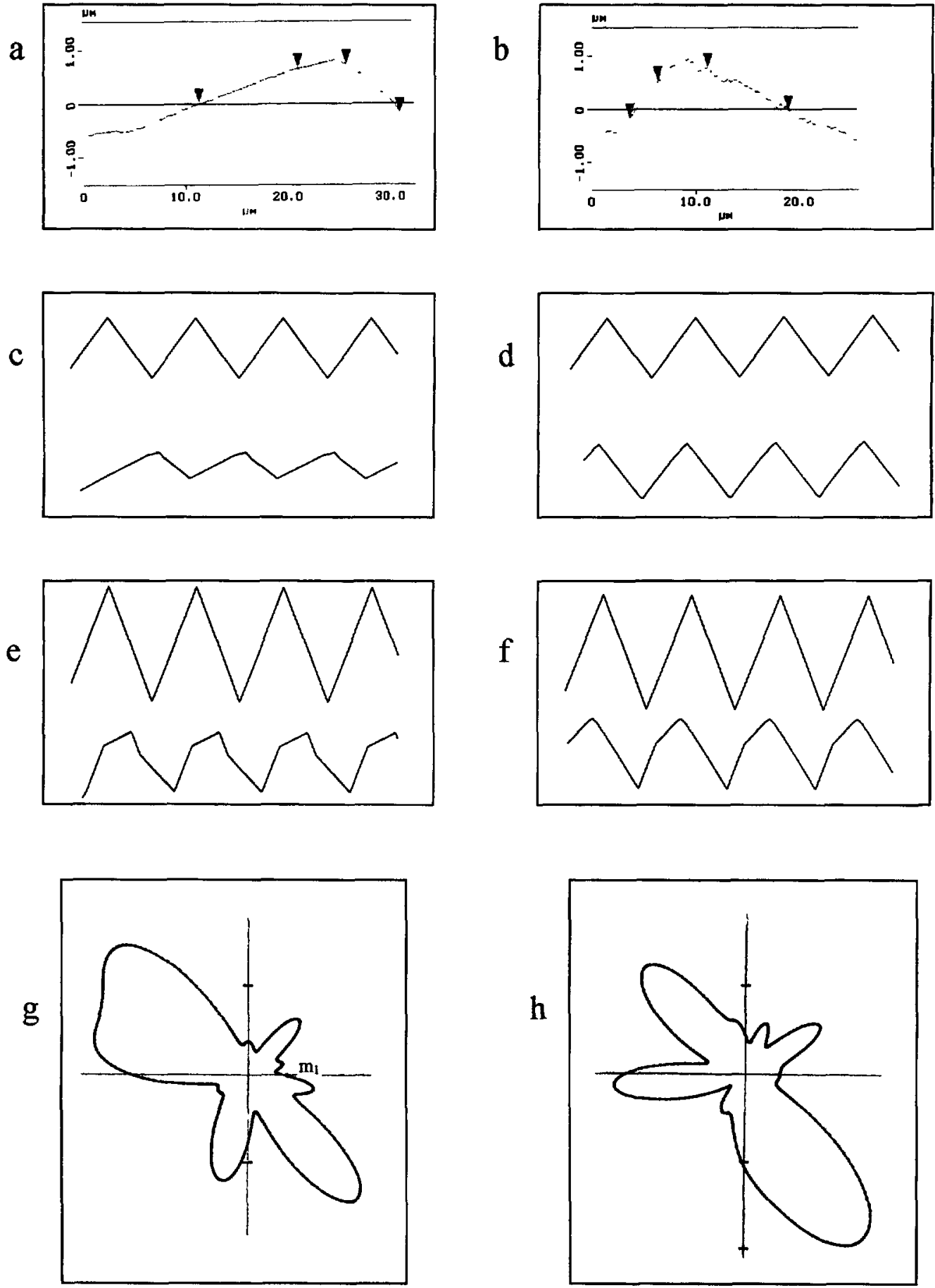

Fig $17-$ Experimental and theoretıcal surface profiles of $Y+40 \mathrm{cut}$, negative face. Experimental profile along the direction $\psi=40^{\circ}$ (a) and $\psi=-50^{\circ}$ (b) Theoretical profile with $\alpha_{\max }= \pm 15^{\circ}$ along the direction $\psi=40^{\circ}$ (c) and $\psi=-50^{\circ}$ (d) Theoretıcal profile with $\alpha_{\max }= \pm 30^{\circ}$ along the direction $\psi=40^{\circ}(\mathrm{e})$ and $\psi=-50^{\circ}$ (f) Polar plot corresponding to the $\psi=40^{\circ}(\mathrm{g})$ and $\psi=-50^{\circ}$ (h) profiles 
a
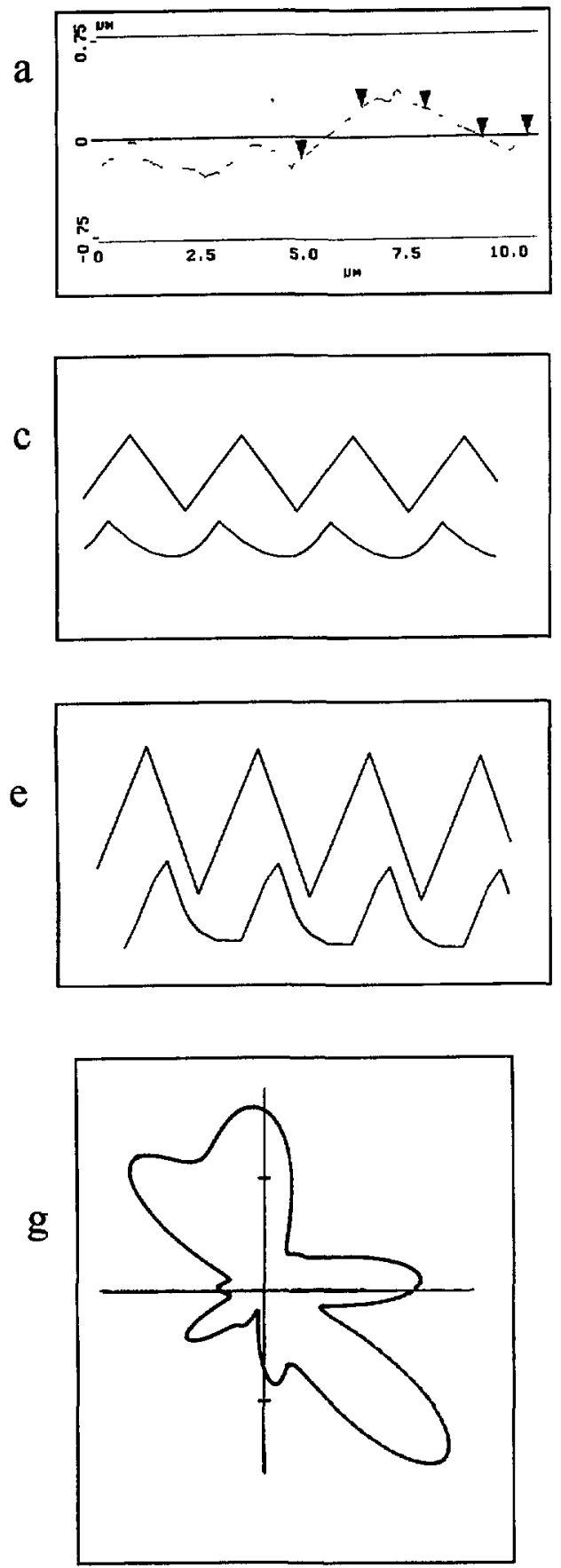

b
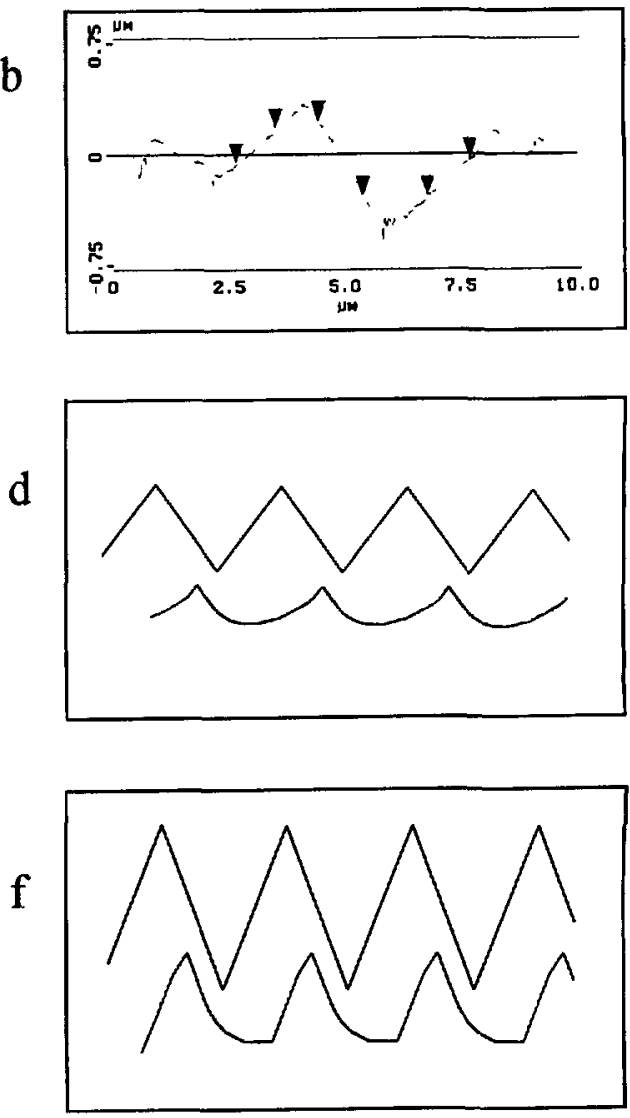

$\mathrm{h}$

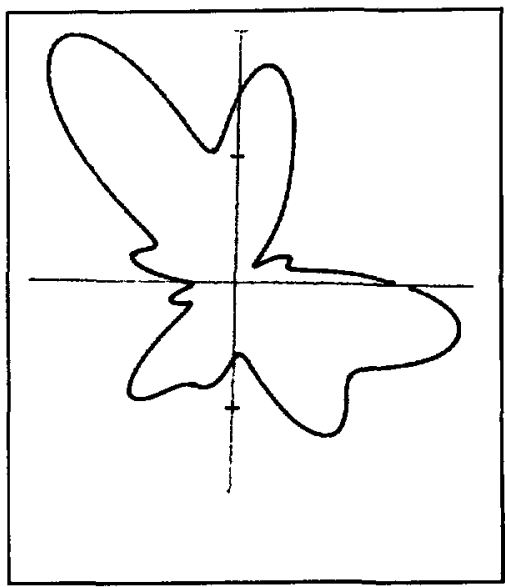

Fig 18. - Experimental and theoretical surface profiles of $Y+40$ cut, positive face. Experımental profile along the direction $\psi=35^{\circ}$ (a) and $\psi=-55^{\circ}$ (b) Theoretical profile with $\alpha_{\max }= \pm 15^{\circ}$ along the direction $\psi=35^{\circ}$ (c) and $\psi=-55^{\circ}$ (d) Theoretical profile with $a_{\max }= \pm 30^{\circ}$ along the direction $\psi=35^{\circ}(\mathrm{e})$ and $\psi=-55^{\circ}(\mathrm{f})$. Polar plot corresponding to the $\psi=35^{\circ}(\mathrm{g})$ and $\psi=-55^{\circ}(\mathrm{h})$ profiles 
a

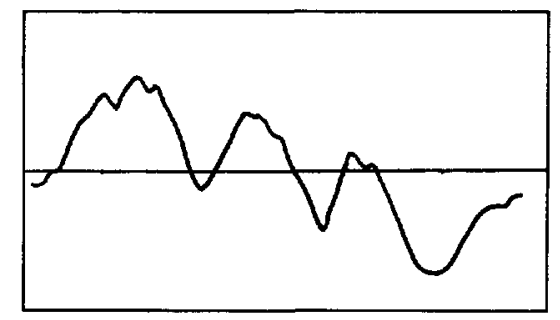

c
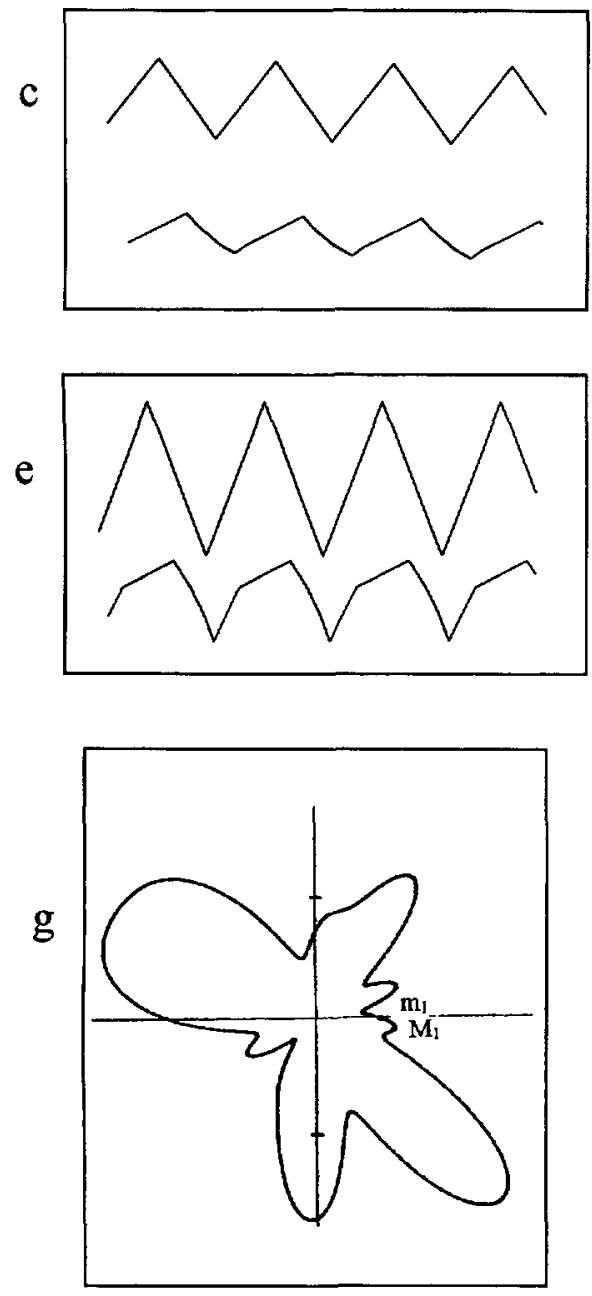

b

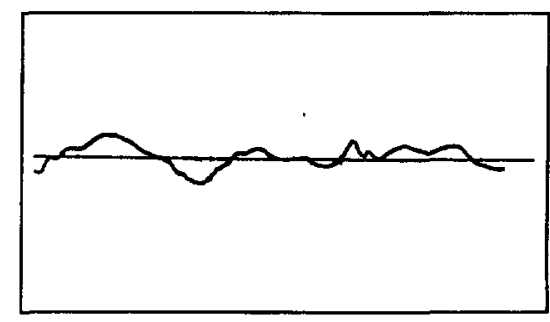

d
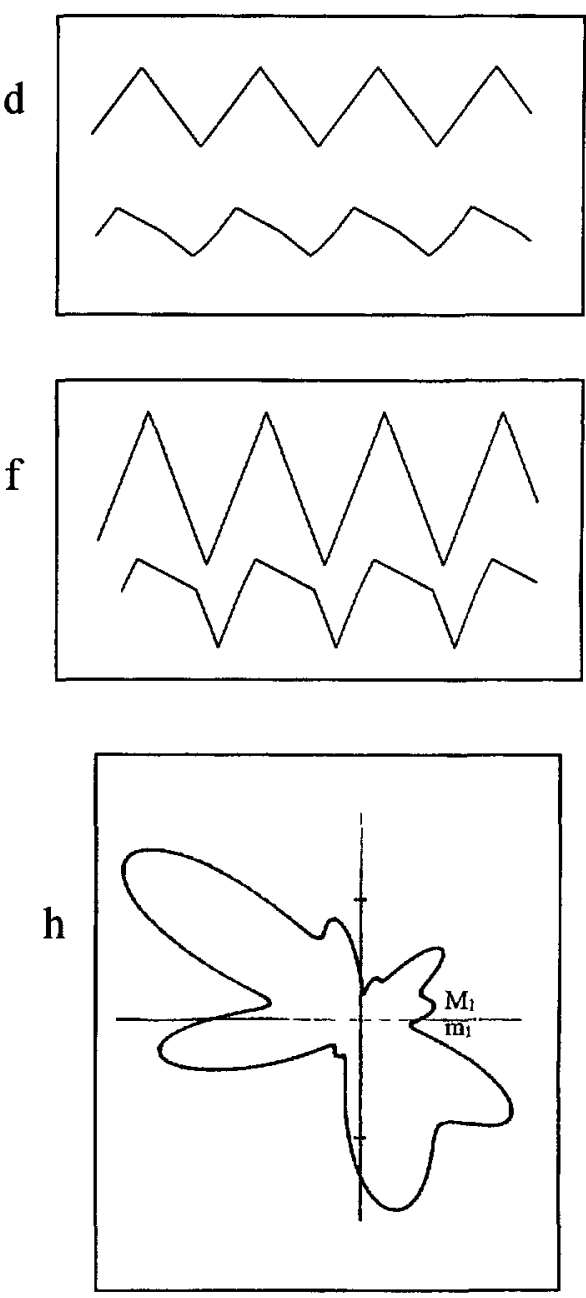

Fig. 19. - Experimental and theoretical surface profiles of $Y+30$ cut, negative face. Experımental profile along the direction $\psi=54^{\circ}$ (a) and $\psi=-36^{\circ}$ (b). Theoretical profile with $\alpha_{\max }= \pm 15^{\circ}$ along the direction $\psi=54^{\circ}$ (c) and $\psi=-36^{\circ}$ (d). Theoretical profile with $\alpha_{\max }= \pm 30^{\circ}$ along the direction $\psi=54^{\circ}$ (e) and $\psi=-36^{\circ}$ (f). Polar plot corresponding to the $\psi=54^{\circ}$ (g) and $\psi=-36^{\circ}$ (h) profiles 

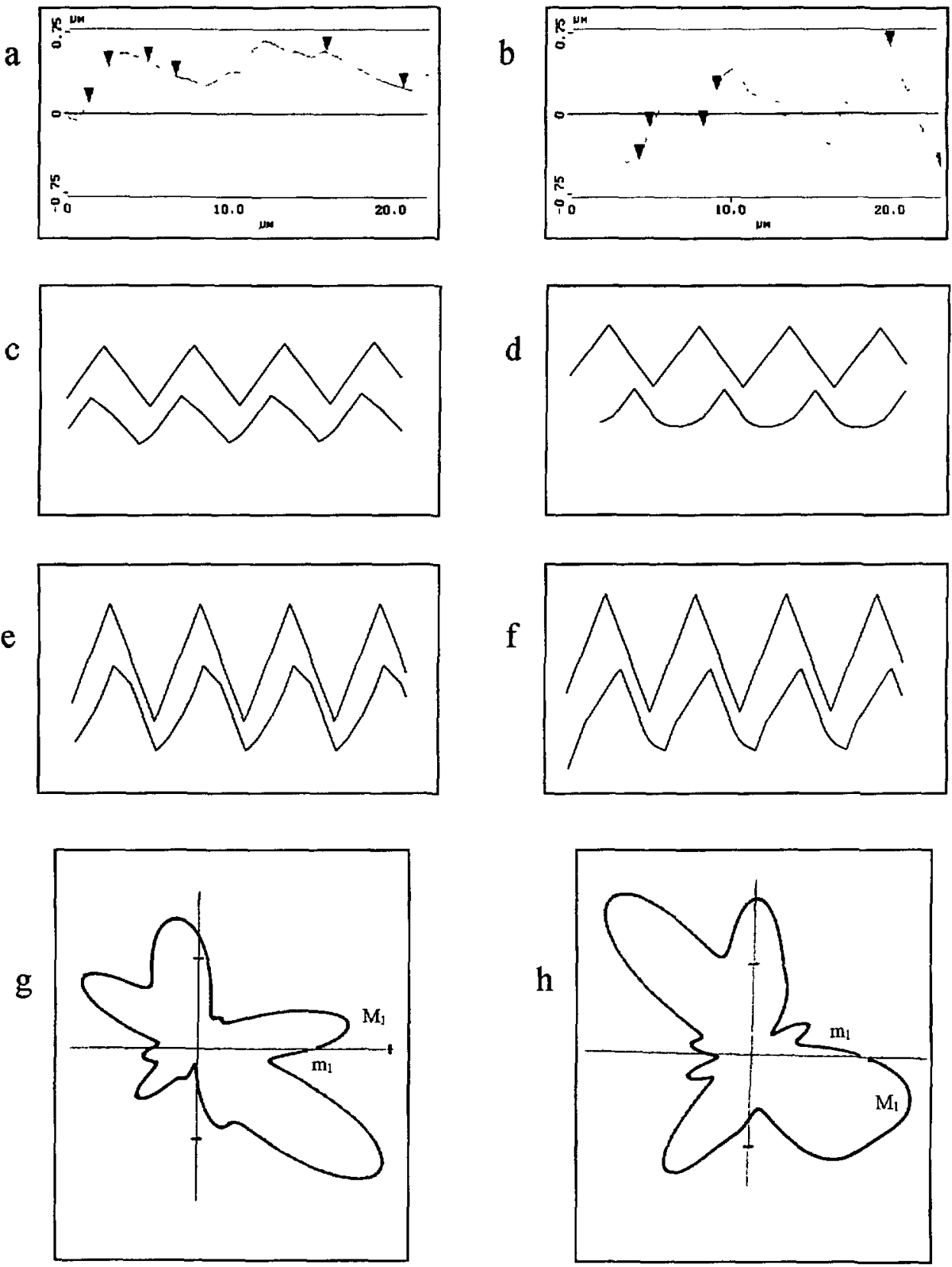

Fig 20. - Experimental and theoretıcal surface profiles of $Y+30$ cut, positive face Experimental profile along the drrection $\psi=+32^{\circ}$ (a) and $\psi=-58^{\circ}$ (b). Theoretical profile with $\alpha_{\max }= \pm 15^{\circ}$ along the direction $\psi=+32^{\circ}$ (c) and $\psi=-58^{\circ}$ (d) Theoretical profile with $\alpha_{\max }= \pm 30^{\circ}$ along the direction $\psi=+32^{\circ}$ (e) and $\psi=-58^{\circ}$ (f) Polar plot corresponding to the $\psi=+32^{\circ}$ (g) and $\psi=-58^{\circ}(\mathrm{h})$ profiles 


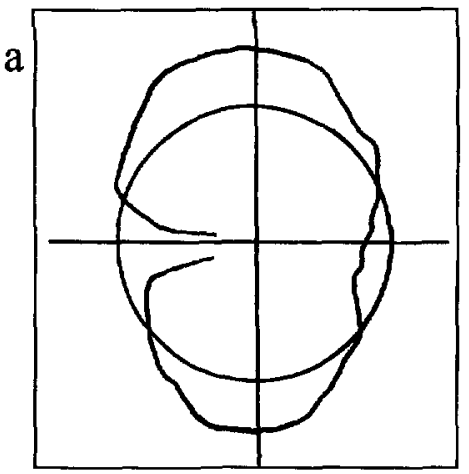

b

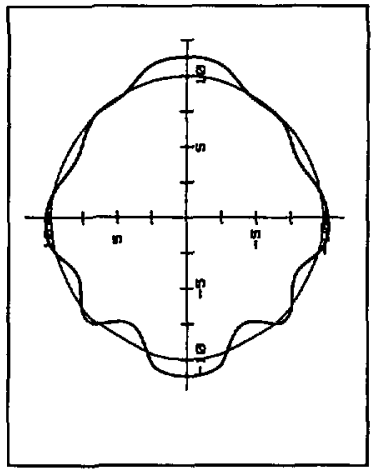

d

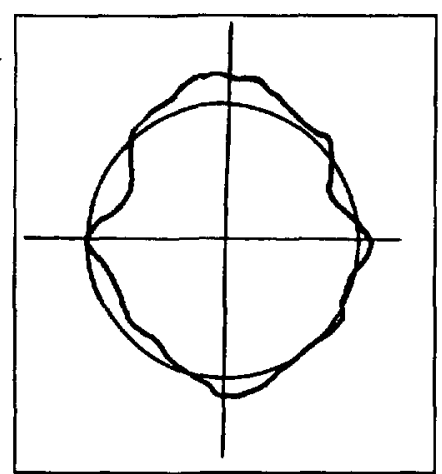

g

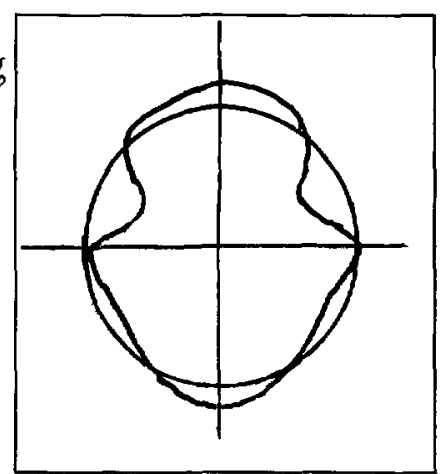

e

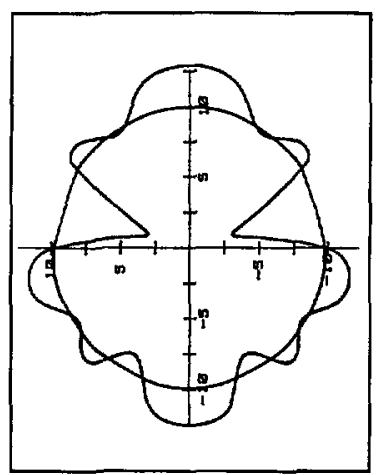

h

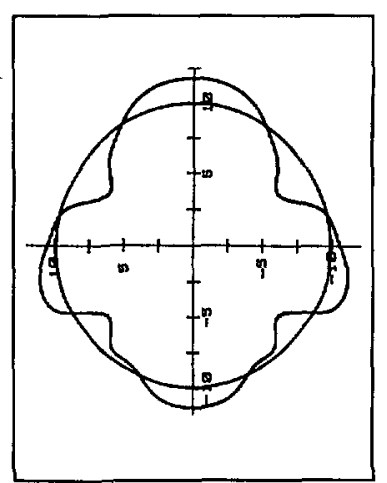

c

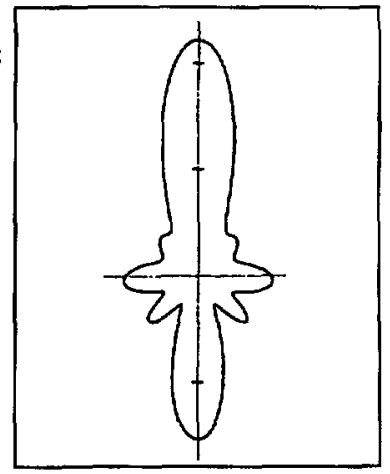

f
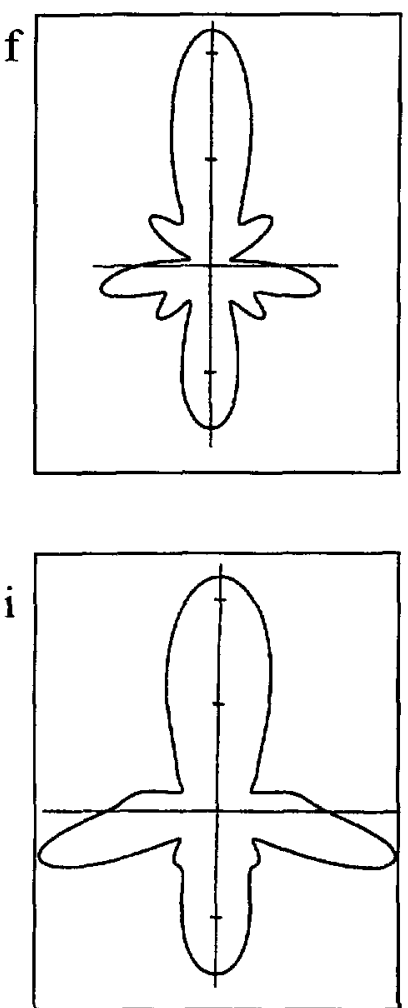

Fig. 21. - Experimental out-of-roundness graphs for AT-21 (a), AT-35 (d) and AT-50 (g) cuts. Theoretical profiles $(\mathrm{b}, \mathrm{e}, \mathrm{h}$ ) respective to the polar plots lying in the cross-sectional planes AT-21 (c), AT-35 (f) and AT-50 (1) 


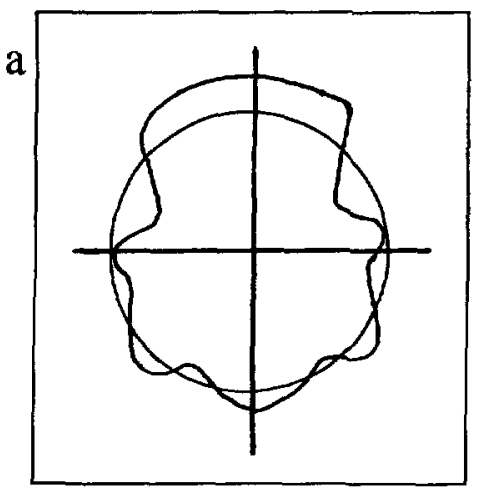

b

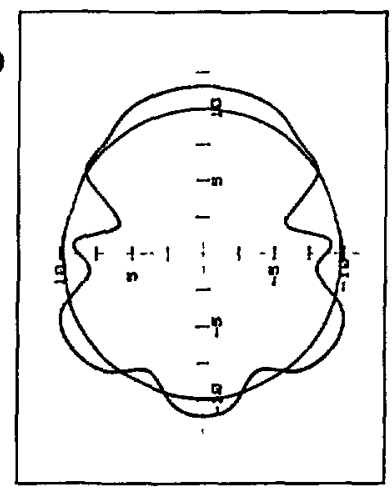

d
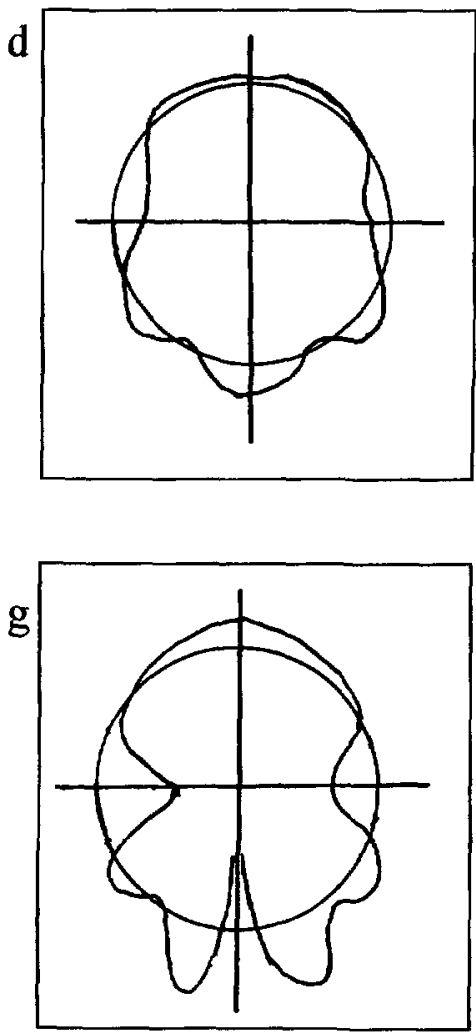

e

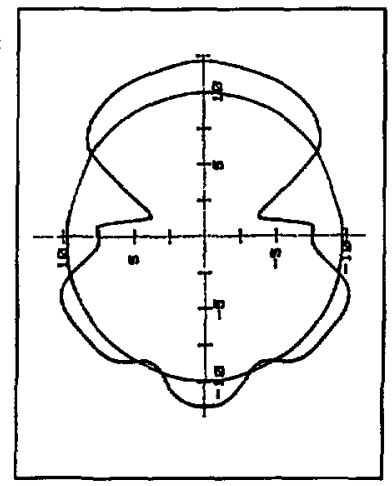

h

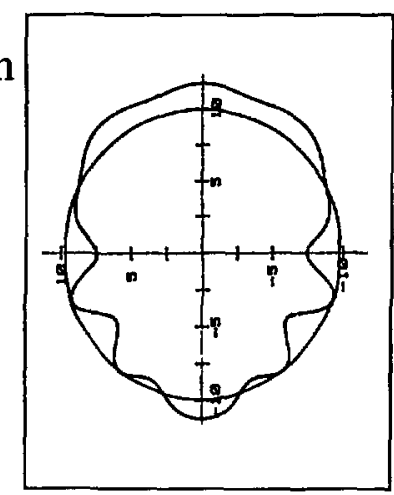

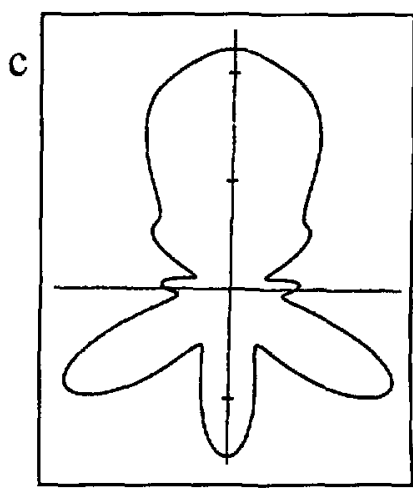

f
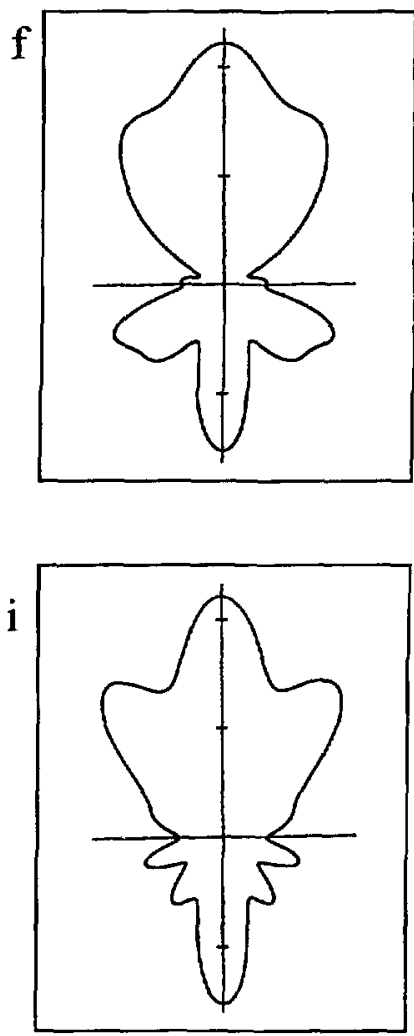

Fig 22 - Experimental out-of-roundness graphs for BT-45 (a), BT-30 (d) and BT-14 (g) cuts Theoretical profiles $(b, e, h)$ respective to the polar plots lying in the cross-sectional planes BT- 45 (c), $\mathrm{BT}-30$ (f) and BT-14 (1) 
a

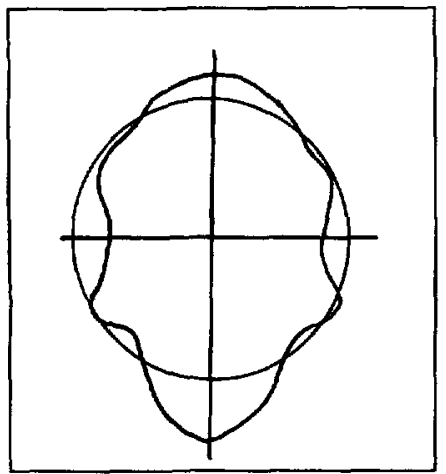

d

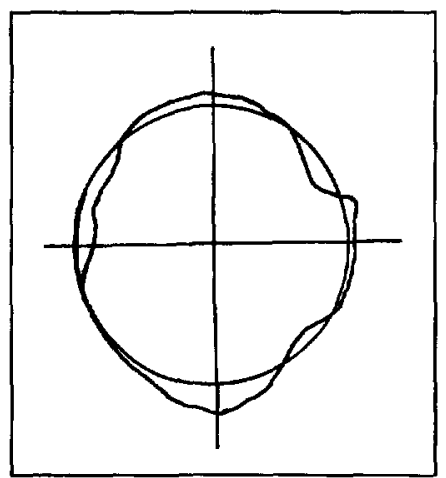

$\mathrm{g}$

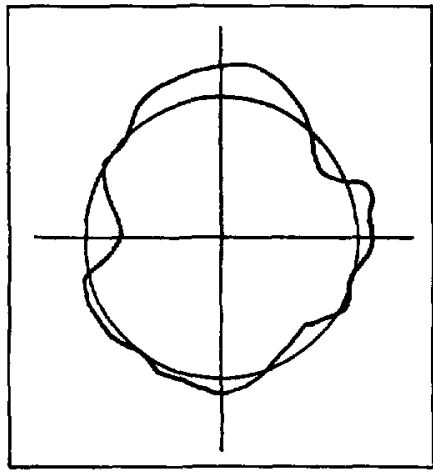

b

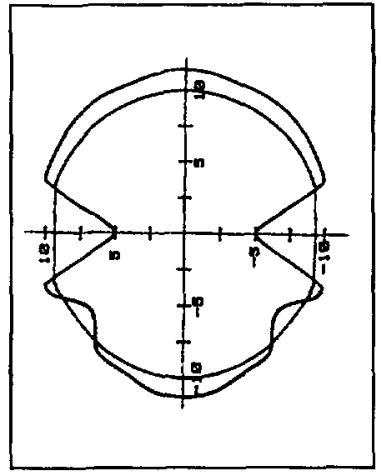

e

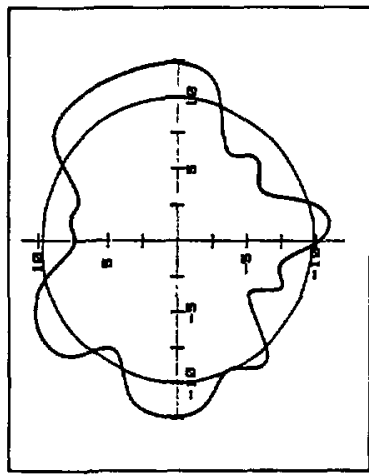

h

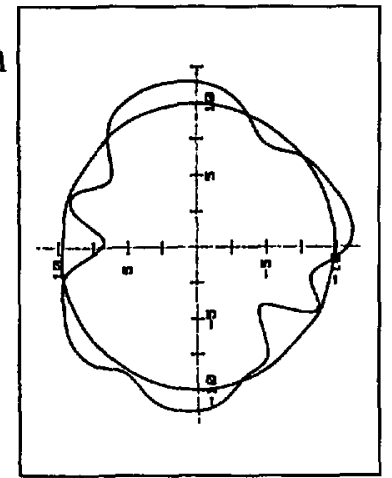

c

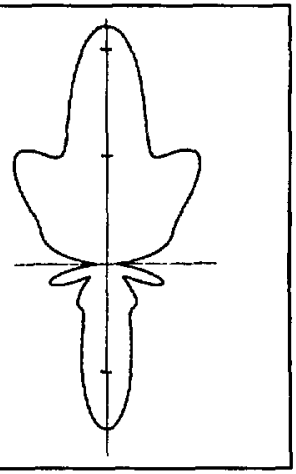

f
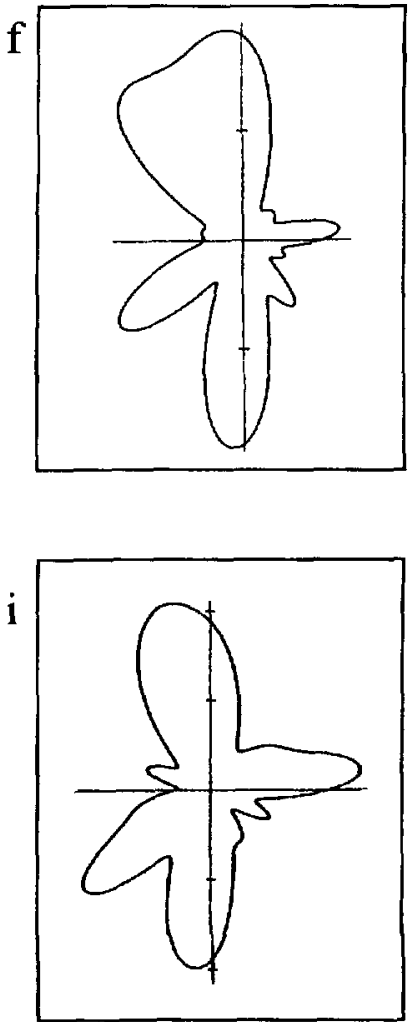

Fig 23 - Experimental out-of-roundness graphs for $Y$ (a), $Y+30$ (d) and $Y+50$ (g) cuts Theoretical profiles $(b, e, h)$ respective to the polar plots lving in the cross-sectional planes $Y(c), Y+30$ (f) and $Y+50(\mathrm{i})$. 
Table VII. - Angles of mınıma in out-of-roundness profiles - Reduced magnıtudes of mınıma.

\begin{tabular}{|c|c|c|c|c|c|c|c|c|c|c|c|}
\hline $\begin{array}{c}\text { Quartz plates } \\
\text { (degrees) }\end{array}$ & \multicolumn{6}{|c|}{$\begin{array}{l}\text { Theoretical angles of minima } \psi \\
\text { (degrees) } \\
\text { Reduced magnitude } L \text { of minima } \\
\text { of polar plot }\end{array}$} & \multicolumn{5}{|c|}{$\begin{array}{l}\text { Experimental angles of mimma } \\
\qquad \psi \text { (degrees) } \\
\text { Reduced magnitude } L \text { of } \\
\text { minıma of out-of-roundness }\end{array}$} \\
\hline$\varphi_{0}=0^{\circ} \quad \theta_{0}=-45^{\circ}$ & $\begin{array}{l}\psi=25 \\
L=1.8\end{array}$ & $\begin{array}{l}80 \\
1.4 \\
\end{array}$ & $\begin{array}{l}110 \\
1 \\
\end{array}$ & & & & $\begin{array}{l}\psi^{\prime}=25 \\
L=1.1\end{array}$ & $\begin{array}{l}70 \\
1.1 \\
\end{array}$ & $\begin{array}{l}110 \\
1 \\
\end{array}$ & & \\
\hline$\varphi_{0}=0^{\circ} \quad \theta_{0}=-30^{\circ}$ & $\begin{array}{l}\psi=25 \\
L=2\end{array}$ & $\begin{array}{l}110 \\
1 \\
\end{array}$ & & & & & $\begin{array}{l}\psi=30 \\
L=11\end{array}$ & $\begin{array}{l}110 \\
1 \\
\end{array}$ & & & \\
\hline$\varphi_{0}=0^{\circ} \quad \theta_{0}=-14^{\circ}$ & $\begin{array}{l}\psi=20 \\
L=15\end{array}$ & $\begin{array}{l}50 \\
1 \\
\end{array}$ & $\begin{array}{l}90 \\
1 \\
\end{array}$ & $\begin{array}{l}160 \\
35 \\
\end{array}$ & & & $\begin{array}{l}\psi=40 \\
L=1.6\end{array}$ & $\begin{array}{l}90 \\
1 \\
\end{array}$ & $\begin{array}{l}160 \\
1.8 \\
\end{array}$ & & \\
\hline$\varphi_{0}=0^{\circ} \quad \theta_{0}=0^{\circ}$ & $\begin{array}{l}\psi=50 \\
L=2\end{array}$ & $\begin{array}{l}90 \\
1 \\
\end{array}$ & $\begin{array}{l}155 \\
1.1 \\
\end{array}$ & & & & $\begin{array}{l}\psi=50 \\
L=1.1\end{array}$ & $\begin{array}{l}90 \\
1 \\
\end{array}$ & $\begin{array}{l}145 \\
1.2 \\
\end{array}$ & & \\
\hline$\varphi_{0}=0^{\circ} \quad \theta_{0}=20^{\circ}$ & $\begin{array}{l}\psi=30 \\
L=1\end{array}$ & $\begin{array}{l}60 \\
1 \\
\end{array}$ & $\begin{array}{l}120 \\
11 \\
\end{array}$ & $\begin{array}{l}150 \\
1.4 \\
\end{array}$ & & & $\begin{array}{l}\psi=45 \\
L=1.6\end{array}$ & $\begin{array}{l}65 \\
1 \\
\end{array}$ & $\begin{array}{l}110 \\
1.1\end{array}$ & $\begin{array}{l}140 \\
15 \\
\end{array}$ & \\
\hline$\varphi_{0}=0^{\circ} \quad \theta_{0}=35^{\circ}$ & $\begin{array}{l}\psi=30 \\
L=2\end{array}$ & $\begin{array}{l}55 \\
2.5 \\
\end{array}$ & $\begin{array}{l}105 \\
1 \\
\end{array}$ & $\begin{array}{l}150 \\
25 \\
\end{array}$ & & & $\begin{array}{l}\psi=35 \\
L=13\end{array}$ & $\begin{array}{l}60 \\
13 \\
\end{array}$ & $\begin{array}{l}110 \\
1 \\
\end{array}$ & $\begin{array}{l}150 \\
13 \\
\end{array}$ & \\
\hline$\varphi_{0}=0^{\circ} \quad \theta_{0}=50^{\circ}$ & $\begin{array}{l}\psi=50 \\
L=2\end{array}$ & $\begin{array}{l}120 \\
1 \\
\end{array}$ & & & & & $\begin{array}{l}\dot{\psi}=55 \\
L=1.2\end{array}$ & $\begin{array}{l}110 \\
1\end{array}$ & & & \\
\hline$\varphi_{0}=90^{\circ} \quad \theta_{0}=30^{\circ}$ & $\begin{aligned} \psi & =20 \\
L & =16 \\
\psi & =250 \\
L & =1.1\end{aligned}$ & $\begin{array}{l}55 \\
1 \\
270 \\
1\end{array}$ & $\begin{array}{l}75 \\
12 \\
330 \\
1.4 \\
\end{array}$ & $\begin{array}{l}120 \\
1\end{array}$ & $\begin{array}{l}150 \\
1\end{array}$ & & $\begin{aligned} \psi & =55 \\
L & =1 \\
\psi & =230 \\
L & =1.2\end{aligned}$ & $\begin{array}{l}100 \\
1.1 \\
280 \\
1 \\
\end{array}$ & $\begin{array}{l}140 \\
1 \\
310 \\
1 \\
\end{array}$ & & \\
\hline$\varphi_{0}=90^{\circ} \quad \theta_{0}=50^{\circ}$ & $\begin{array}{l}\psi=50 \\
L=1\end{array}$ & $\begin{array}{l}75 \\
1.5 \\
\end{array}$ & $\begin{array}{l}110 \\
15 \\
\end{array}$ & $\begin{array}{l}235 \\
13 \\
\end{array}$ & $\begin{array}{l}270 \\
1 \\
\end{array}$ & $\begin{array}{l}330 \\
15\end{array}$ & $\begin{array}{l}\psi=50 \\
L=1\end{array}$ & $\begin{array}{l}105 \\
1 \\
\end{array}$ & $\begin{array}{l}135 \\
1 \\
\end{array}$ & $\begin{array}{l}275 \\
1\end{array}$ & $\begin{array}{l}315 \\
12 \\
\end{array}$ \\
\hline
\end{tabular}

in the simulation, we start with all the surface elements which are tangent to the starting circular cross-section corresponding to cuts defined by the angles $\left(\varphi_{0}, \theta_{0}\right)$. So, we work with a polar plot of $\mathbf{L}$ lying $\mathrm{in}$ the planes defined by $\left(\varphi_{0}, \theta_{0}\right)$. The initial starting sections can be decomposed into successive convex intersections. Thus, according to Irving criteria [45], the final shape of an etched cross-section is composed partly by limiting facets associated with minima in the cross-sectional polar plot of $\mathbf{L}$ These facets correspond to valleys in the outof-roundness. It seems of interest to verify if the values of theoretical and experimental angles related to valleys are in agreement for the cuts investigated here (Tab. VII). A rapid comparison of theoretical and experimental out-of-roundness profiles shows a crude accord specially for AT and BT cross-sectional shapes. We can remark that the experimental data contain errors specially for doubly-rotated cuts for which a Flat Mark (F.M.) has been made to recognize the direction of $X^{\prime}$-axis

We can also discuss the reduced amplitude of successive minima in $L$ in $\left(\varphi_{0}, \theta_{0}\right)$ polar graphs as compared with reduced amplitude of successive valleys in out-of-roundness profiles. These amplitudes are evaluated for each cross-sections with respect to the more accentuated minima or with respect to the deeper valley. Examination of Table VII reveals that the more marked 

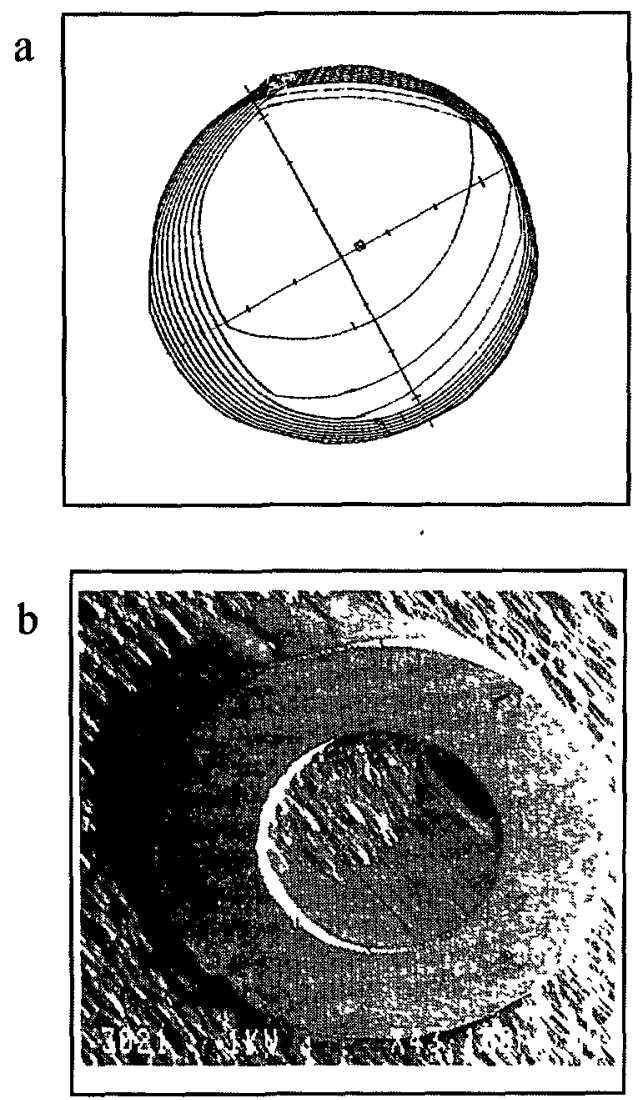

Fig 24. - Three-dimensional numerical simulation: constant level contours for membrane (a) etched on a $Y+30$ plate. Corresponding experimental result (b).

minima of polar plot are correlated to the more pronounced valleys in the experimental out-ofroundness profiles. But, the other valleys which are less marked cannot be precisely evaluated. In conclusion, we can say that the angles of the primary minima of polar plots can be deduced from corresponding experimental out-of-roundness profiles. Other informations must be taken with some care.

\section{Conclusion}

The previous results can be summarized as follow.

a) The observation of surface profiles gives a lot of informations concerning the polar plot diagrams, such as:

- the presence of minima or maxima of $\mathbf{L}$ for the reference surface which is characteristic of a convex or concave profile,

- the presence of extrema in the vicinity of the orientation $\left(\varphi_{0}, \theta_{0}\right)$ which gives rise to alternate convex-concave or concave-convex profiles. The symmetry of the profile indicates that the extrema are situated symmetrically with respect to the reference 
slowness in the polar plot. The analysis of slope distributions on profiles will give complementary informations (See Part I of this paper).

Nevertheless, we recall that the analysis of surface profiles must be taken with care because a lot of artefacts occurs as Section 4 gives evidence.

b) Concerning the out-of-roundness profiles, we can conclude that they give a crude image of the polar plots. We obtain angular positions of marked minima but minor perturbations of the polar plot cannot be depicted.

The comparison of theoretical simulation and experimental profiles is rather satisfactory. Some departures between theory and experimental data appear for doubly-rotated cuts around $\left(\varphi_{0}=90^{\circ}, \theta_{0}=30^{\circ}\right)$. Thus amplitudes and angular positions of extrema in the slowness surface must be adjusted in a small angular sector to obtain a complete adequation with experimental results. But, with the $2 \mathrm{D}$ simulation and the previous experimental results, the degree of accuracy in the amplitude and position of minor extrema is very difficult to estimate. So, we have to undertake complementary experiments. It seems particularly interesting to study the localized etching at a mask. Specially comparison of experimental 3D shapes for micromachined structure like mesa or holes with the $3 \mathrm{D}$ shapes derived from numerical simulation $[21,47,48]$ appears to be very convenient. To illustrate this purpose, we present a membrane etched in the $Y+30$ cut starting with a circular mask (Fig. 24b), and the corresponding 3D numerical simulation (Fig. 24a). Here the etching shape is representated with a constant level contours diagram for hole.

The two pictures are in good agreement. We propose to report several experimental micromachmed structures (mesa, holes, convex or concave undercutting...), and to discuss the advantages that a $3 \mathrm{D}$ simulation offers in a future paper.

\section{References}

[1] Vig J.R., Wasshausen W., Cook C., Katz M. and Hafner E., Surface preparation and characterization techniques for quartz resonators, in Proc. of the 27th Annu. Symp. on Freq. control, Fort Monmouth, NJ, 1973 (Electronic Industries Association, Washington DC, 1973) pp. 98-112.

[2] Vig J.R., Lebus J.W and Filler R F., Chemically Polished quartz, in Proc of the 31st Annu. Symp. on Freq. Control, Fort Monmouth, NJ, 1977 (Electronic Industries Association, Washington DC, 1977) pp. 131-143.

[3] Fukuyo H. and Oura N., Surface layer of a polished cyrstal plate, in Proc. of the 30th Annu Symp, on Freq. Control, Fort Monmouth, NJ. 1976 (Electronic Industries Association, Washington DC, 1976) pp. 254-258.

[4] Brandmayr R.J. and Vig J R., Further investigation of etchants for chemically polishing SC-cut quartz crystals, in report DELET-TR 81-16, Fort Monmouth (US Army Electronics command 1981) pp. 1-14.

[5] Tellier C.R., Effect of crystal orientation on the surface texture of chemically etched quartz plates: the case of cuts close to the AT-cut, in Proc. of the 39th Annu. Symp. on Freq. Control, Philadelphia, PA, 1985 (Institute of Electronic and Electrical Engineers, NY, 1985) pp. 282-291.

[6] Tellier C.R., Jouffroy F. and Buron C., Some effects of chemical etching on the surface texture of SC-cut and RT-cut quartz plates, Mat. Chem. Phys. 14 (1986) 25-40. 
[7] Tellier C.R. and Buron C., Etch figures on BT-cut quartz plates: evidence for asymmetrıcal etch rate distributions, Surf. Techn. 22 (1984) 287-298.

[8] Tellier C.R., Surface texture of chemically etched AT-cut quartz plates, Surf. Tech. 21 (1984) 83-89.

[9] Castagliola M., Tellier C.R. and Vaterkowski J.L., The topography of etched rhombohedral faces of quartz crystals - Evidence for orientation effects, J. Mat. Sci. 21 (1986) 3551-3560.

[10] Tellier C.R. and Vaterkowski J.L., Influence of initial surface damage on the final texture of chemically etched quartz plates, Surf. Technol. 26 (1985) 275-285

[11] Tellier C R., Etch figures and etch rates in AT, BT, $X$ and $Y$ cut quartz plates, Proc. of the 38th Annu. Symp. on Freq. Control, Philadelphia, PA, 1984 (Institute of Electronic and Electrical Engineers, NY, 1984) pp. 105-113.

[12] Vondeling J.K , Fluoride-based etchants for quartz, J. Mater. Scr. 18 (1983) 304-314.

[13] Wegner M W and Christie M., Chemical etchıng of deformation sub-structures in quartz, Phys. Chem. Minerals 9 (1983) 67-78.

[14] Josh1 M.S and Vag A.S., Application of the selective etch method in the study of structural defects in synthetic quartz, Soviet Physics Crystallography 12 (1968) 573-580

[15] Petersen K.E, Silicon as a mechanical material, Proc. IEEE 70 (1982) 420-457.

[16] Delapierre G., Micromachining: a survey of the most commonly used processes, Sens. Actuators 17 (1989) 123-138.

[17] Schnakenberg U., Benecke W. and Lòchel B., $\mathrm{NH}_{4} \mathrm{OH}$-based etchants for silicon micromachining, Sens. Actuators A21-A23 (1990) 1031-1035.

[18] Studer B. and Zingg W., Technology and characteristics of chemically milled miniature quartz crystals, Proc of the 4th European Freq. and Time Forum, Neuchâtel Suisse, 1990 (Fondation Suisse pour la Recherche en Microtechnique. 1990) pp. 653-658

[19] Ueda T., Kohsaka F., Yamasaki D. and Iino T., Quartz crystal micromechanical devices, Proc. 3rd Int. Conf on Solid State Sensors and Actuators (Philadelphia PA, 1985) pp. $113-116$

[20] Danel J S., Michel F. and Delapierre G, Micromachining of quartz and its application to an acceleration sensor, Sens. Actuators A21-A23 (1990) 971-977.

[21] Tellier C.R., Messaoudi T. and Leblois T., Contribution of a 3D numerical simulation to the design of micromachined quartz microstructures, Proc. of the 10 th EFTF, Brighton, UK, 1996 (To be published)

[22] Leblois T., Tellier C. and Bourquin R., The quality factor of deeply etched quartz resonators; theory and experiments, Rev. Phys. Appl. 24 (1989) 877-892.

[23] Hunt J.R. and Smythe R.C., Chemically milled VHF and UHF AT-cut resonators, Proc. 39th Annu. Symp. on Freq. Control, Philadelphia, PA, 1985 (Institute of Electronic and Electrical Engineers, NY, 1985) pp. 282-291

[24] Wu X. and Ko W., Compensating corner undercutting in ansotropic etching of (100) silicon, Sens. Actuators 18 (1989) 207-215.

[25] Frank F., in R.H Doremus, B W. Roberts and D. Turnbull, Eds., Growth and perfection of crystals (John Wiley, New-York, 1958) pp 411-419.

[26] Jacodine R.J., Use of modified free energy theorems to predict equilibrium growing and etching shapes, J. Appl. Phys. 33 (1962) 2643-2647.

[27] Shaw D.W., Morphology analysis in localized growth and dissolution, J. Cryst. Growth 47 (1979) 509-517.

[28] Heimann R.B., in J Grabmaier, Ed, Silicon chemical etching (Springer, Berlin, 1982) pp. 197-207.

[29] Tellier C.R. and Vaterkowski J.L., A tensorial representation of the dissolution slowness Application to etched singly rotated quartz plates, J. Mater. Sci. 24 (1989) 1077-1088. 
[30] Brahim-Bounab A., Amaudrut J.Y. and Tellier C.R., The dissolution slowness surface of cubic crystals. Part II: Applications to class 23 and to combined etching and lithography techniques, J. Mater. Sci. 26 (1991) 5595-5607

[31] Tellier C.R., Vialle N. and Vaterkowski J.L., A vectorial analysis for the numerical simulation of the surface profiles of etched singly-rotated quartz plates, Surf. Coat Tech. 34 (1988) 417-439.

[32] Ueda T., Kohsaka F., Tino T. and Yamazaki D., Theory to predict etching shapes in quartz and application to design devices, Trans. Soc. Inst. Control Eng. 23 (1987) 1-6.

[33] Leblois T. and Tellier C.R., Determmation of the dissolution slowness surface by study of etched shapes. Part. I: Morphology of the dissolution slowness surface and theoretical etched shapes, J. Phys. III France 2 (1992) 1259-1286.

[34] Tellier C.R. and Brahim-Bounab A., Anisotropic etching of silicon crystals in $\mathrm{KOH}$ solution. Part II: Theoretical two dimensional etched shapes: discussion of the adequation of the dissolution slowness surface, J. Mater. Sc 29 (1994) 6354-6378.

[35] Shaw D., Localized GaAs etching with Acidic Hydrogen Peroxide solutions, J. Electrochem. Soc 128 (1981) 874-880.

[36] Csepregi L., Micromechanics: a silicon microfabrication technology, Microelectron. Eng. 3 (1985) 221-234.

[37] Tellier C.R., Etching of semiconductor cubic crystals. Determination of the dissolution slowness surfaces, J. Cryst. Growth 100 (1990) 515- 526.

[38] Standard on piezoelectricity (IEEE, New-York, 1978) pp. 15-27.

[39] Sangwal K, Etching of crystals, Chap. 11 (North-Holland, Amsterdam, 1987).

[40] Tellier C.R. and Jouffroy F., Orientation effects in chemical etching of quartz plates, $J$. Mater. Sci. 18 (1983) 3621-3632.

[41] Sekigughi Y. and Funakubo H., Strained surface layers of quartz plates produced by lapping and polishing and their influence on quartz resonator performance, J. Mater. Scz. 15 (1980) 3066-3070.

[42] Fukuyo H. and Oura N., Surface layer of a polished crystal plate, in Proc. of the 30th Annu. Symp. on Frequency Control, Fort Monmouth, NJ, 1976 (Electronic Industries Association, Washington DC, 1976) pp. 254-258

[43] Batterman B.W., Hillocks, pits and etch rate in Germanium crystals, J. Appl. Phys. 28 (1957) 1236-1241.

[44] Irving B.A., In The Electrochemistry of semiconductors, P J. Holmes, Ed. (London, Academic Press, 1962) pp. 256-289.

[45] Tellier C.R., Leblois T. and Maitre P.C., Dissolution shapes of $Y$-rotated quartz plates and $Y$ sections derived from the polar diagram of the dissolution slowness, J. Mat. Scl. 24 (1989) 3029-3039.

[46] Leblois T., Maitre P. and Tellier C.R., Simulation of the contour shape for etched quartz crystals. Proc. of 2nd Europ. Freq. and Time Forum, Besançon France, 1989 (Conseil Général du Doubs, 1989) pp. 41-49.

[47] Tellier C.R. and Durand S., Microfabricated silicon structures. experimental and theoretıcal investigations of 3D etched shapes, Proc. of 9th EFTF Besançon France, 1995 (Conseil Général du Doubs, Besançon) pp. 426-429

[48] Messaoudi T., Leblons T. and Tellier C.R.. Chemical etching of $Y$-rotated quartz plates orientation effects on $2 \mathrm{D}$ and $3 \mathrm{D}$ shapes, in Proc. Eurosensors $\mathrm{X}, 10^{\text {th }}$ European Conference on Solid-State transducers (Leuven Belgium, 1996) pp 195-198. 